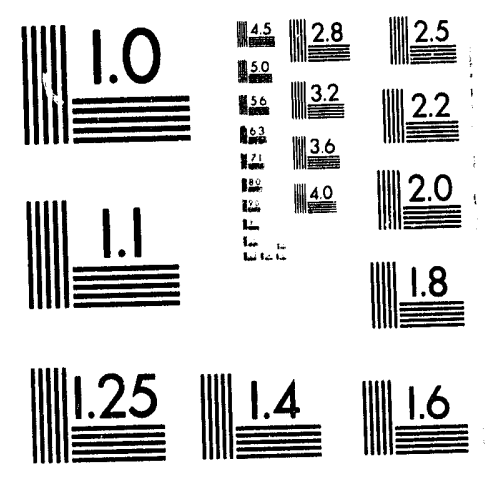



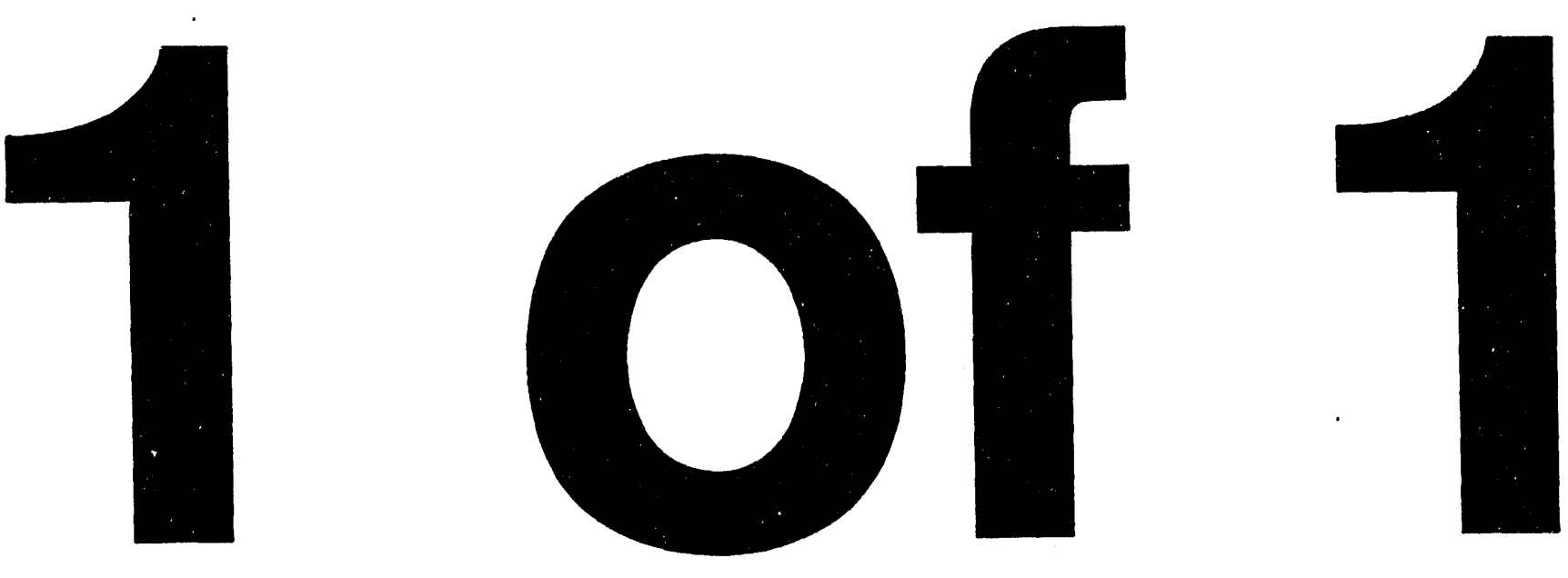
SAND93-2073

Distribution

Unlimited Release

Category UC-706

Printed February, 1994

\title{
Using Monte Carlo Techniques and Parallel Processing for Debris Hazard Analysis of Rocket Systems
}

\author{
Robert A. LaFarge \\ Flight Dynamics Department \\ Sandia National Laboratories \\ Albuquerque, New Mexico 87185
}

\begin{abstract}
Sandia National Laboratories has been involved with rocket systems for many years. Some of these systems have carried high explosive onboard, while others have had FTS for destruction purposes whenever a potential hazard is detected. Recently, Sandia has also been involved with flight tests in which a target vehicle is intentionally destroyed by a projectile. Such endeavors always raise questions about the safety of personnel and the environment in the event of a premature detonation of the explosive or an activation of the FTS, as well as intentional vehicle destruction. Previous attempts to investigate fragmentation hazards for similar configurations have analyzed fragment size and shape in detail but have computed only a limited number of trajectories to determine the probabilities of impact and casualty expectations. A computer program SAFETIE has been written in support of various SNL flight experiments to compute better approximations of the hazards. SAFETIE uses the AMEER trajectory computer code and the Engineering Sciences Center LAN of Sun workstations to determine more realistically the probability of impact for an arbitrary number of exclusion areas. The various debris generation models are described.
\end{abstract}




\section{Acknowledgment}

The author would like to thank R. Rabie of Los Alamos National Laboratories for providing the explosive velocity used in the analysis as well as for providing the Mott distribution model used to determine fragment size. D. E. Outka and J. K. Cole, both of the Flight Dynamics Department at Sandia National Laboratories, provided invaluable assistance in the STARS and LEAP analyses, respectively.

This work performed at Sandia National Laboratories, which is operated for the U.S. Department of Energy under contract number DE-AC04-94AL85000. 


\section{Table of Contents}

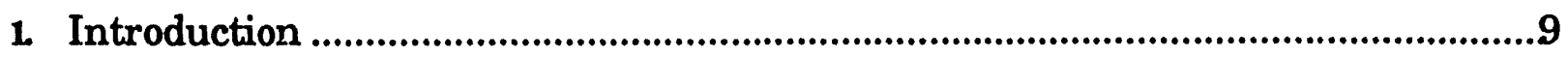

2. The Explosive Debris Model …...........................................................................13

2.1 Velocity Model ....................................................................................................14

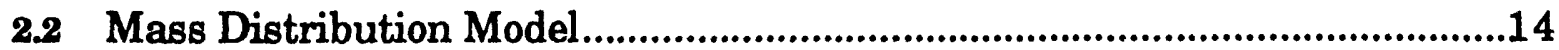

2.3 Comparison to A Previous Casualty Analysis .................................................16

2.4 SAFETIE Fragment Size and Shape..............................................................17

2.5 Fragment Trajectory Initial Conditions.................................................19

3. The Missile Breakup Debris Model ..........................................................................23

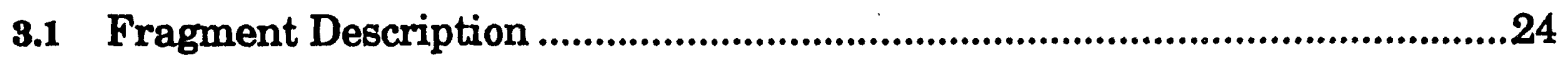

3.2 Summary of STARS M1 Results..................................................................26

4. Vehicle Impact Debris Breakup Model......................................................................37

4.1 Debris Breakup Models ....................................................................................37

4.2 FAST Debris Breakup Model.......................................................................41

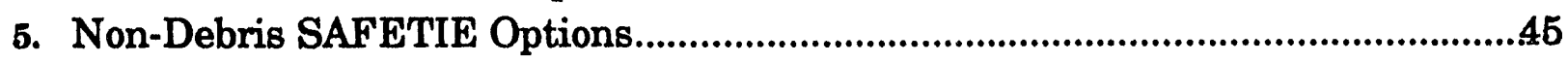

5.1 Vehicle State Vector Options ......................................................................45

5.2 Atmosphere and Winds Options .................................................................46

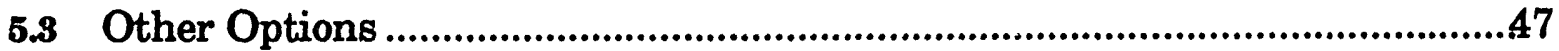

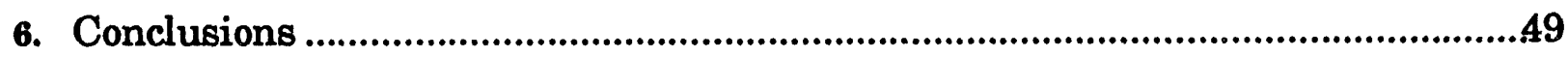

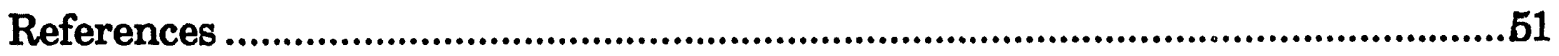

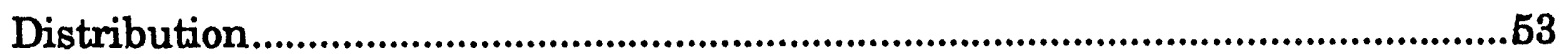




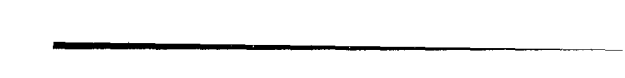

$\bullet$

•

2 


\section{List of Figures}

Figure 1.1: ZEST Configuration. ..................................................................................11

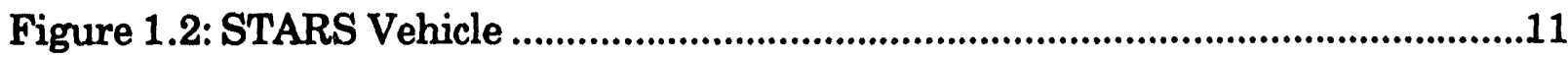

Figure 1.3: LEAP Vehicle ..............................................................................................11

Figure 2.1: ZEST Fragment Mass DIstribution ..............................................................13

Figure 2.2: High Altitude ZEST Impact Pattern.............................................................15

Figure 2.3: Low Altitude ZEST Impact Pattern .........................................................16

Figure 2.4: Explosive Velocity Vector Relative to the Body Reference Frame ..........19

Figure 3.1: STARS M1 Approaching Kwajalein .............................................................24

Figure 3.2: Incremental Velocity Relative to the Body Reference Frame....................25

Figure 3.3: The Orbus 1 STARS Third Stage Motor ......................................................26

Figure 3.4: Debris Impacts for STARS M1 Hard Over Nozzle Failure Mode with Four Second Delay . 29

Figure 3.5: Debris Impacts for STARS M1 Stuck Nozzle Failure Mode with Four Second Delay ..................................................................................................30

Figure 3.6: Debris Impacts for STARS M1 Null Position Nozzle Failure Mode with Four Second Delay .31

Figure 3.7: Debris Impacts for STARS M1 Instantaneous Destruct Failure Mode with Four Second Delay ...........................................................................................32

Figure 3.8: STARS M1 Probability Density Contours for Four Second Delay ...........33

Figure 4.1: FAST and IMPACT Mass Distribution.......................................................38

Figure 4.2: Mass/Diameter Relationships for FAST and IMPACT ...........................39

Figure 4.3: IMPACT Spread Velocity Distribution .......................................................40

Figure 4.4: FAST Spread Velocity Model.....................................................................41

Figure 4.5: LEAP Debris Dispersion for Ten Monte Carlo Intercepts .........................44 


\section{Introduction}

Sandia National Laboratories (SNL) has been involved in the launching of guided and unguided rocket systems for over 35 years. Some of these systems, such as the Strategic Defense Initiative Office (SDIO) sponsored ZEST flight test program, ${ }^{1,2}$ have had high explosive (HE) onboard. ZEST vehicles, which were launched from the SNL Kauai Test Facility (KTF) in the summer and fall of 1991, had about 255 pounds of $\mathrm{HE}$ aboard a Talos-Castor launch vehicle (Figure 1.1). A premature detonation of the $\mathrm{HE}$ could have caused debris to disperse to several of the neighboring islands. Other systems, such as the SNL STARS (Strategic TARget System) ${ }^{3,4}$ (Figure 1.2) have flight termination systems (FTS), which are to be activated by the missile flight safety officer (MFSO) whenever the trajectory unexpectedly deviates beyond predetermined bounds. The debris caused by this action could disperse into populated areas. Programs, such as the series of LEAP (Lightweight ExoAtmospheric Projectile) (Figure 1.3) flight tests at White Sands Missile Range (WSMR), ${ }^{b}$ purposely try to destroy a target vehicle by having LEAP impact it. This creates debris which can have ground impacts outside WSMR. Naturally, such undertakings raise questions about the safety of personnel, equipment, and the environment. While no flight test has zero risk, experimenters have a responsibility to assess accurately the hazards of any experiment. Consequently, the ability to determine realistically $P_{I}$, the probability of a piece of debris impacting a given exclusion area, is an important factor in the safety analysis of any flight test in which that debris could be potentially hazardous. Once $P_{I}$ is known, the casualty expectation $\left(\mathrm{E}_{\mathrm{C}}\right)$ can be computed based on local demographics. The probability $P_{I}$ can be computed as $P_{E}$, the probability of a having the event (determined by reliability studies), multiplied by $\mathrm{P}_{\mathrm{I} / \mathrm{E}}$, the probability of impact given that the event has taken place. For the three examples, the probability of a premature detonation of the HE or the probability of a STARS system failure causing a large deviation in the trajectory are much smaller than one, while the probability of LEAP hitting itis target vehicle is very close to one.

Two computer codes, SAFETIE (Sandia Analysis of Fragment and Ejecta TrajectorIEs) and PDF (Probability Density Function) have been written at SNL to compute debris dispersion and to determine casualty expectation. The debris dispersion code SAFETIE is a preprocessor to the AMEER ${ }^{6,7,8}$ (Aero Mechanical Equations Evaluation Routines) trajectory computer code. SAFETIE computes files of trajectory initial conditions generated in a Monte Carlo sense for a sample size of $\mathrm{n}$ events, each containing $\mathrm{m}$ debris fragments. The trajectories can be computed in a parallel processing environment using the Engineering Sciences Center local area network (LAN) of Sun workstations. If 40 workstations are used, results for 1000 explosions with 127 fragments per explosion can be obtained overnight for no cost, as opposed to requiring about 40 hours of computational time on the SNL Cray YMP. $\mathrm{PDF}$ is a postprocessor that uses an AMEER output file generated by SAFETIE to 
determine a statistical model of the impact likelihood on the earth's surface. Although results from PDF will be shown, only SAFETIE will be discussed in this report. The three empirical models (explosion, FTS activation, and vehicle impact) in SAFETIE for generating debris will be discussed, and results from previous range analyses will be shown. Some of the other options that add to the versatility of SAFETIE will also be discussed.

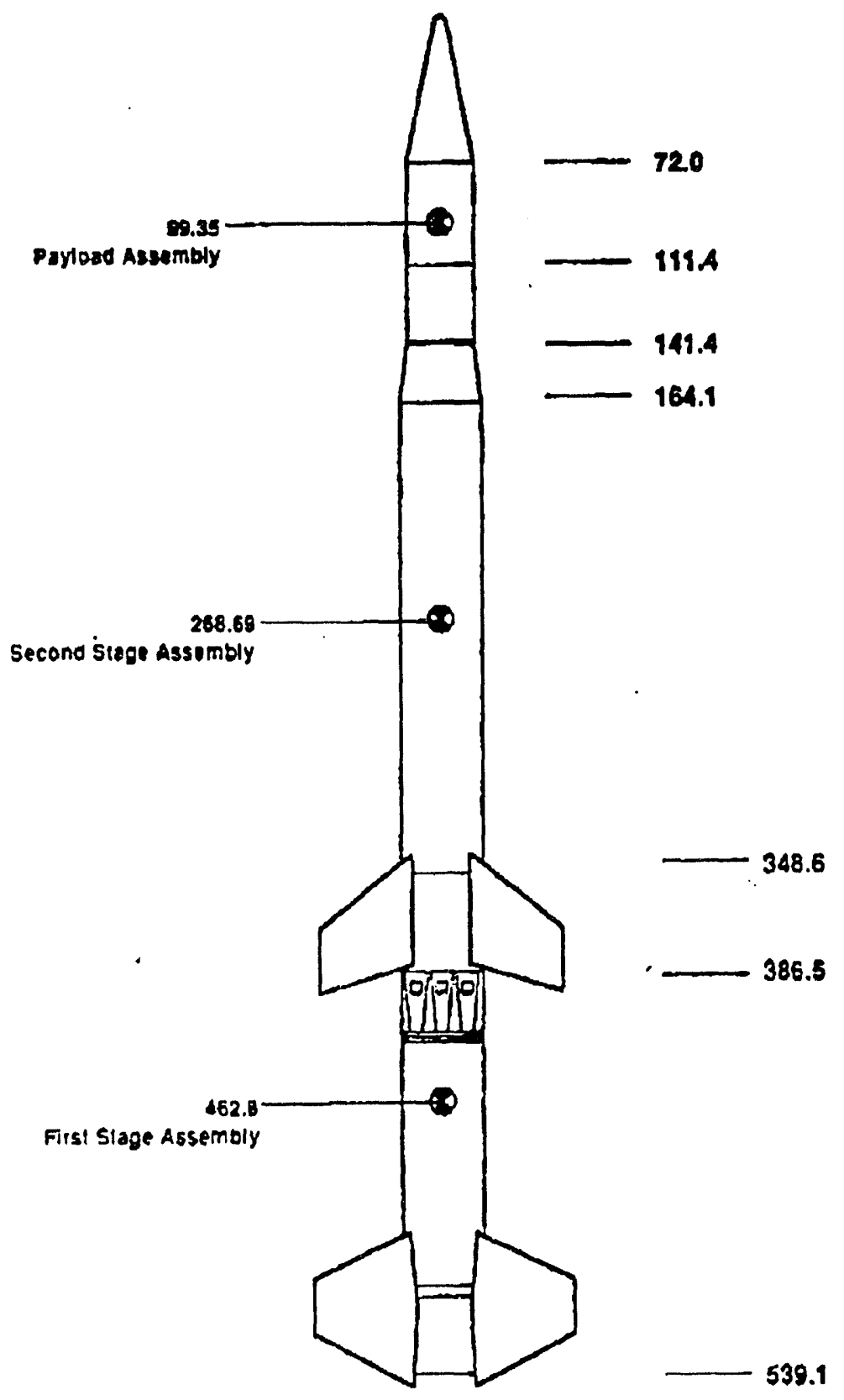

Figure 1.1: ZEST Configuration. 


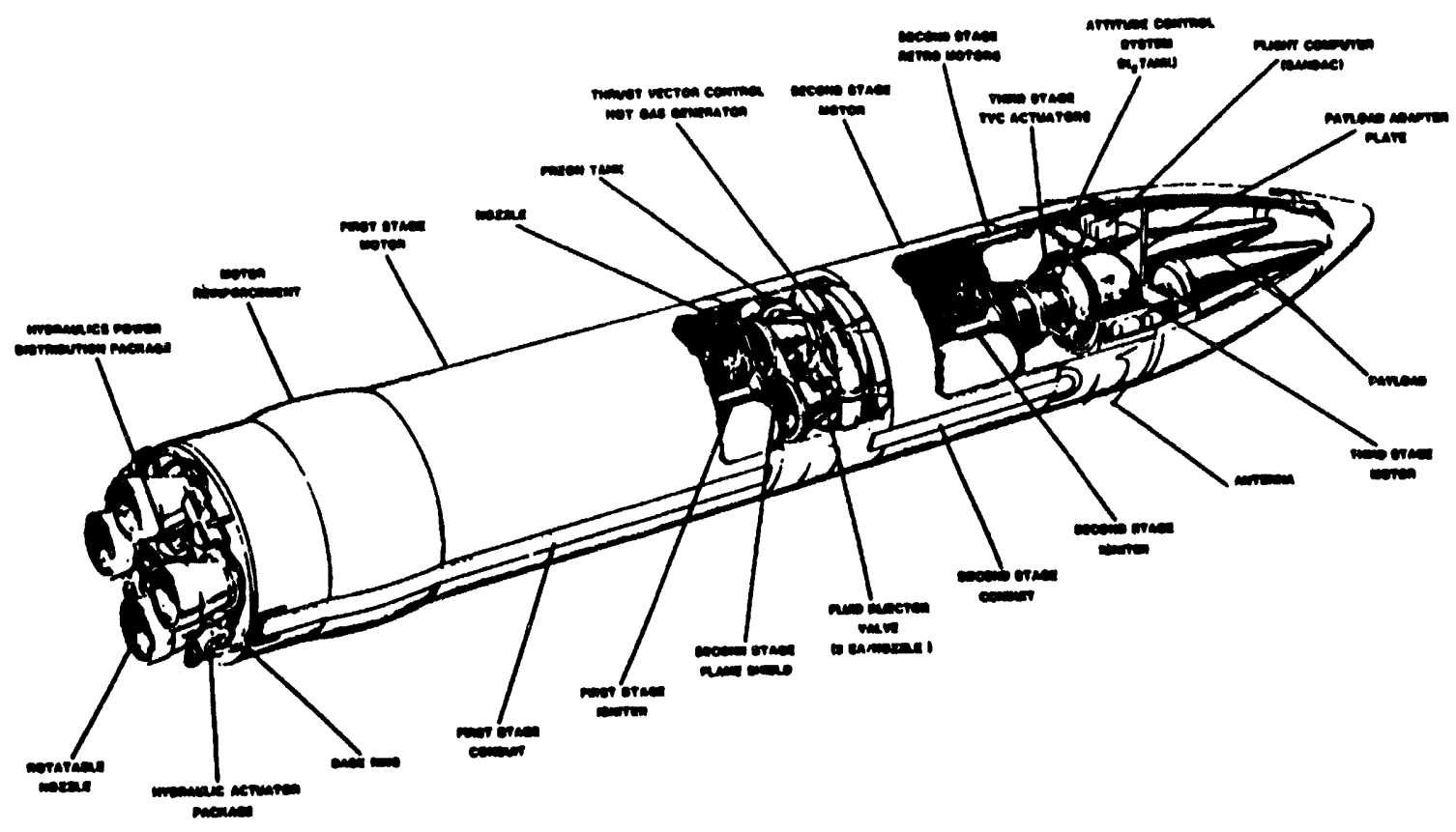

Figure 1.2: STARS Vehicle

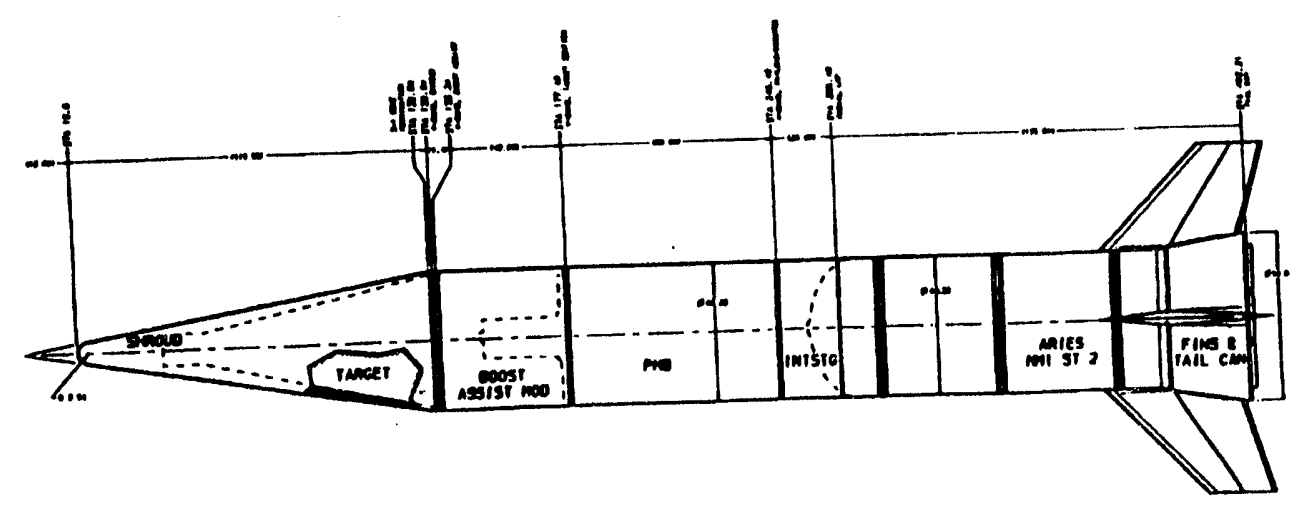

Figure 1.3: LEAP Vehicle 


$$
\text { }
$$




\section{The Explosive Debris Model}

SNL has previously investigated the hazards due to premature detonation of $\mathrm{HE}$ onboard a rocket system. ${ }^{9,10}$ Although neither previous investigation had the scope of investigation that users currently have with SAFETIE, they both computed the basic parameters that SAFETIE uses. The basic parameters include a velocity model and a mass distribution model. For this SAFETIE option, the velocity model is a constant explosive velocity $\left(V_{0}\right)$, and the mass model is usually a Mott distribution:

$$
N(m)=\frac{M}{2 M_{0}^{2}} \mathrm{e}^{-\sqrt{\frac{m}{M_{0}^{2}}}}
$$

where $N(m)$ is number of fragments of mass $m$ or greater, $M$ is the total mass to be fragmented, and $M_{0}$ is a Mott constant. ${ }^{11}$ The constant $M_{0}$ can be given by:

$$
M_{0}=B_{2} t^{\frac{5}{6}} d^{\frac{1}{3}}\left(1+\frac{t}{d}\right)
$$

where $B_{2}$ is a constant depending on the explosive (between 0.21 and 0.35 for TNT), $d$ is the internal diameter of the casing, and $t$ is the wall thickness. Mott computed the total number of fragments to be $M /\left(2 M_{0}^{2}\right)$ and, consequently, the average fragment mass to be $2 M_{0}^{2}$. Figure 2.1 is an example of a typical Mott distribution. Randall ${ }^{9}$ derived similar models for his fragmentation hazards analysis; he just lacked the present computer capabilities to expand his analysis beyond KTF. Nevertheless, a comparison of his analysis with SAFETIE should help assure users that the code's HE model compares well with other investigations.

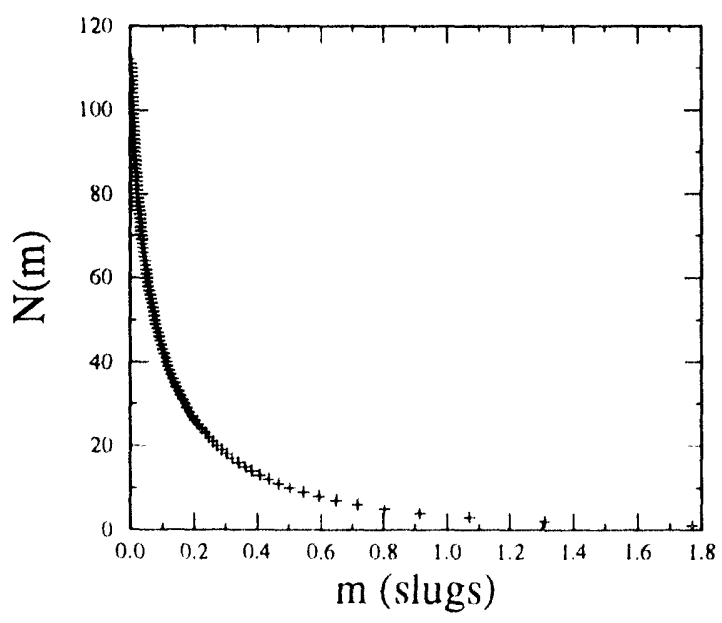

Figure 2.1: ZEST Fragment Mass Distribution 


\subsection{Velocity Model}

Although the fragmentation hazards associated with several explosive payloads launched at KTF have been previously investigated by Randall, he was only concerned with the hazard to personnel and equipment at KTF. His analyses was not extended to the other Hawaiian Islands. The hazard associated with each fragment was characterized as a function of its ballistic coefficient $\left(\beta=W /\left(C_{D} S\right)\right.$, where $W$ is the weight of the fragment, $C_{D}$ is the drag coefficient, and $S$ is the reference area) at impact. To obtain velocity of the fragments issuing from the detonation of the $\mathrm{HE}$, velocity scaling laxy proposed by Weinland and Gurney were both investigated. They were found to differ by no more than $10 \%$. The Gurney equation was used, and it is the scaling law used in the ZEST analysis. It was developed at the Ballistic Research Laboratory and is based on experimental data from bombs and shells. It is given by

$$
V_{0}=\sqrt{2 E R}
$$

with $V_{O}$ being the fragment velocity at the rupture of the case, $E$ representing the contribution to the kinetic energy from a unit mass of the particular explosive, and $R$ representing a configuration factor given by

$$
R=\frac{1}{\frac{W_{M}}{W_{C}}+r_{G}}
$$

with $W_{M} / W_{C}$ representing the ratio of the weight of the metal in the casing wall to the weight of the charge. For a cylindrical warhead, $r_{G}$ is 0.5 , and for a spherical configuration, $r_{G}$ is 0.6 .

For the ZEST analysis, R. Rabie of Los Alamos National Laboratories (LANL) wrote a Macintosh based interactive code to compute fragment velocities based on the Gurney scaling law. The code provides $V_{0}$ as a function of the type and weight of the explosive and the type of material being fragmented. The fragment velocity for the ZEST fragmentation analysis effort is based on a Rabie modification to the Gurney model. The modification accounted for the tungsten/epoxy liner around the $\mathrm{HE}$ in the ZEST configuration. The fragment velocity $V_{0}$ is an input parameter to the SAFETIE preprocessor code.

\subsection{Mass Distribution Model}

Randall next analyzed the mass distribution of the fragments using the Heppner refinement of a Gurney correlation. Its form is very similar to the Mott distribution and is given by: 


$$
N(m)=\frac{M}{m_{0}} \mathrm{e}^{-\sqrt{\frac{2 m}{m_{0}}}}
$$

where $M$ is total fragment mass, and $m_{0}$ is the average fragment mass defined by:

$$
m_{0}=K \frac{D_{0}^{2}}{V_{0}^{2}}
$$

where $D_{0}$ is the outside diameter of payload (inches), $V_{0}$ is the initial velocity ( $\mathrm{ft} / \mathrm{sec}$ ), and $K$ is a constant $\left(6 \times 10^{7}\right)$.

This technique gives the cumulative number of fragments that have a mass greater than $m$. The higher mass fragments of each of two different payload configurations were studied in detail. Only these types of fragments were investigated since they were the only ones capable of being ejected towards the trailer complex at KTF. Trajectories for a matrix of five ballistic coefficients, three altitudes and several elevation angles are computed. The penetration capability of the fragments into the steel roof covering the trailer complex is then thoroughly investigated. Randall concluded that one of the payloads had a low probability of perforating the steel roof with fragments while the other had a very high probability of doing so. No analysis of the fragmentation hazards to other areas was documented in Randall's report.

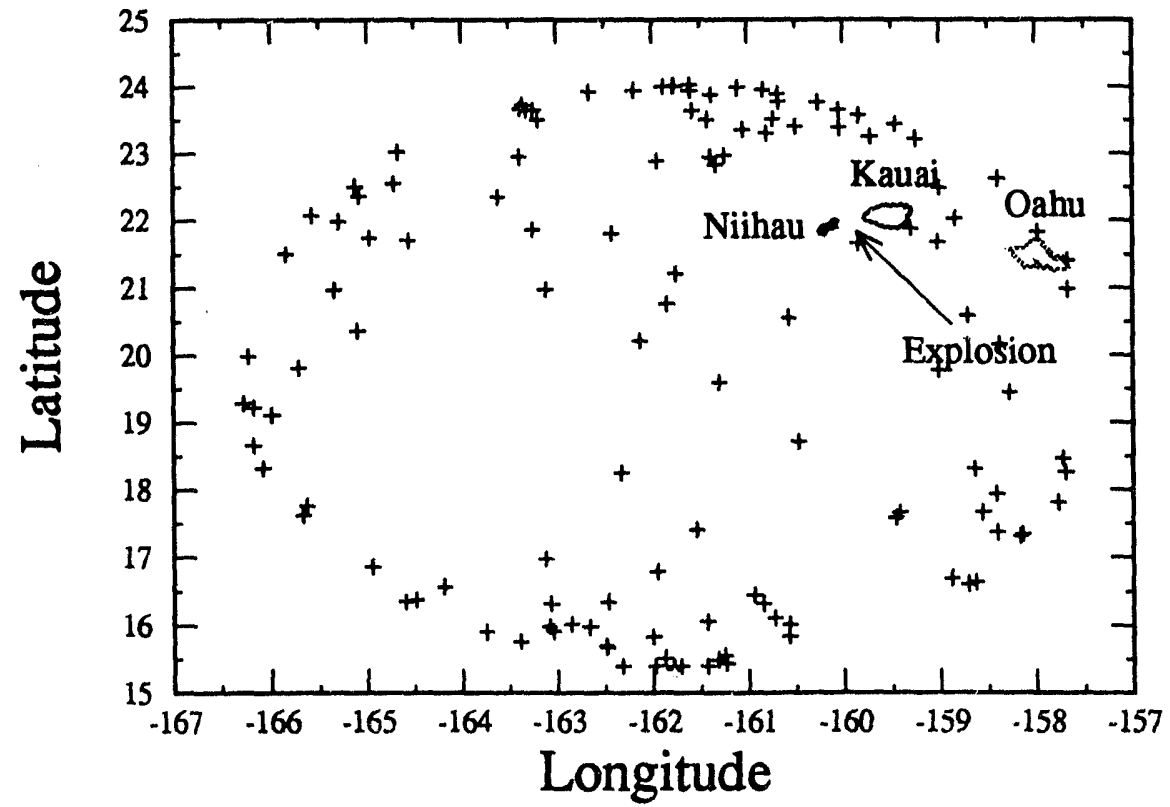

Figure 2.2: High Altitude ZEST Impact Pattern 
While Randall's general philosophy of computing the fragment velocity and mass is followed in SAFETIE, a much broader capability for computing trajectories is available. Fragment trajectories can be computed for an individual explosion or for any specified number of explosions. A single altitude or a random sampling from a user-specified range of altitude can be investigated. Examples of the altitude random sampling for the ZEST safety analysis are shown in Figures 2.2 and 2.3. Figure 2.2 shows the impact pattern for the second explosion (417000 feet altitude) and Figure 2.3 shows the impact pattern for the $19^{\text {th }}$ explosion (10000 feet altitude). The range on the fragment velocity direction can be user-specified, although an isotropic explosion is recommended. An AMEER input file is generated as a result of executing SAFETIE. This AMEER route is highly recommended for a realistic investigation of $P_{I}$ since a parallel processing approach makes the computation of a $P_{I}$ based on 1000 explosions economically possible.

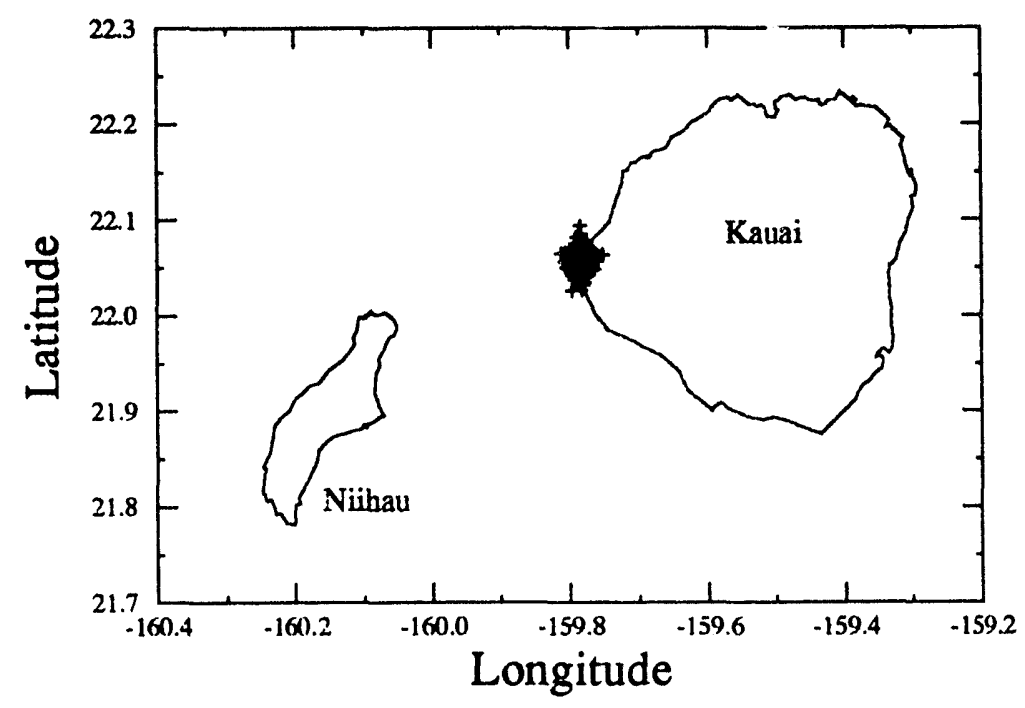

Figure 2.3: Low Altitude ZEST Impact Pattern

\subsection{Comparison to A Previous Casualty Analysis}

Wente ${ }^{10}$ computed the potential fragmentation hazard associated with the Buaro experiment launched from KTF. The experiment contained 348 pounds of HE. The Gurney models proposed by Randall were used to determine the number and size of the fragments. Since the determination of a probability of impacting on land was one of the ultimate goals, the maximum range of the fragments was computed. The probability of impacting on given island $\left(P_{I / P D}\right)$ was determined by

$$
P_{I /(P D)}=1-\left(1-\frac{A_{I}}{\pi R^{2}}\right)^{n}
$$


where $A_{I}$ is the land area of the island of interest, $R$ is the maximum fragment range, and $n$ is the number of fragments. This probability is used with island demographics to compute a casualty expectation. For this experiment, the maximum range was about 525 nautical miles and there were 51 aluminum fragments. Using an area of 467 square nautical miles for the land area of Kauai, Wente computed $P_{I /}$ $P D$ to be $2.7 \%$. If this approach is used for the ZEST experiment, $P_{I / P D}$ is $6.6 \%$. The SAFETIE codes predict $P_{I / P D}$ to be more than $50 \%$ for ZEST.

The problem with the approach used by Wente is that it uses information only from the portion of the trajectory from which the maximum fragment range is computed. Information about how the payload got there (shallow or high angle, low or high acceleration, etc.) is lost. The major advantage in using this method is that it can be done using a pocket calculator, once the maximum range is computed. The approach in the SAFETIE code is more realistic. It uses information from all portions of the trajectory with a uniform probability distribution on the time of the premature detonation; however, the method requires a considerable amount of computer resources.

The SAFETIE preprocessor code borrows its basic philosophy from the MCPRAM ${ }^{8}$ (Monte Carlo PReprocessor for AMEER) preprocessor. Both codes were designed to generate input files for the AMEER trajectory code. The basic difference is that MCPRAM was designed to track just one vehicle at just one initial time while SAFETIE was designed for multiple fragments with multiple initial times. SAFETIE and MCPRAM were designed to facilitate the parallel processing of trajectories. For the investigation of the ZEST flight test, it was estimated that computing 127 fragment trajectories for each explosion would average to about 15 seconds per individual trajectory. Since there were 40 workstations on the LAN, 25 explosions could assigned to each workstation for a study of 1000 explosions. Though it was theoretically possible to use all 40 workstations, only 34 were used per night because some workstations were already being used. The 33 explosions averaged taking about 10 hours per workstation.

\subsection{SAFETIE Fragment Size and Shape}

The basic single explosion computer algorithm on which SAFETIE is based was written by R. Rabie of Los Alamos Scientific Laboratories (LANL) and later modified by the author. Originally, it was constructed to read information about the fragmenting material, compute the size of the largest fragment, and determine fragments that are incremental portions of this size. This analysis used Eq. 2.1 to determine fragment size.

Rabie devised a simple scheme for finding the distribution of the most massive fragments. First, the mass of the largest fragment $\left(m_{1}\right)$ is found by setting $N(m)$ equal to one and solving for $m$ in the Mott formula. 


$$
m_{1}=\left(M_{0} \log \left(\frac{M}{2 M_{0}^{2}}\right)\right)^{2}
$$

The incremental mass $(\delta m)$ is defined to be $m_{1} / 30$. Then, for a counter $(k)$ defined to run from one to thirty, the number fragments that are of mass $m_{k}$ (equal to $\mathrm{k} \delta \mathrm{m}$ ) or greater are subtracted from the number of fragments that are of mass $m_{k-1}$ or greater. This defines $n_{\text {frag }}$, the number of fragments of mass $m_{\text {frag }}$ (equal to the average mass, $(\mathrm{k}-0.5) \delta m)$.

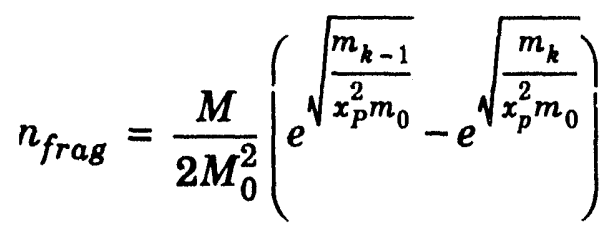

For the ZEST configuration, this algorithm accounts for 127 of the 138 fragments.

If there are no fragments of this particular mass, no further work is done; however if the number of fragments of a particular mass is nonzero, shape parameters for each of the fragments are randomly computed. Three basic shapes with a variation of one the shapes are considered - a sphere, a right circular cylinder, an edge-on cube, and a face-on cube. If $\rho_{f}$ represents the average density of the fragmenting material, then the radius $\left(r_{0}\right)$ and the reference area $(S)$ of a spherical fragment of mass $m_{\text {frag }}$ are

$$
r_{0}=\sqrt[3]{\frac{3 m_{f r a g}}{4 \pi \rho_{f}}} \quad \text { with } S=\pi r_{0}^{2}
$$

The radius and reference area of a unit right circular cylinder are given by

$$
r_{0}=\sqrt[3]{\frac{m_{f r a g}}{2 \pi \rho_{f}}} \text { with } S=\pi r_{0}^{2}
$$

The unit length $\left(x_{0}\right)$ and reference area of a face-on cube are

$$
x_{0}=\sqrt[3]{\frac{m_{f r a g}}{\rho_{f}}} \text { with } S=x_{0}^{2}
$$

The unit length of an edge-on cube is the same; however its reference area is 


$$
S=1.5 x_{0}^{2}
$$

The current implementation of the HE option differs in that Eq 2.1 is solved for the individual mass fragments $\left(m_{i}\right)$

$$
m_{i}=\left(M_{0} \log \left(\frac{M}{i 2 M_{0}^{2}}\right)\right)^{2} \text { for } \quad 1 \leq i<N_{T}
$$

Users have the option of specifying a minimum mass $\left(m_{\min }\right)$ below which fragments are not computed. This is so nonhazardous fragments are not computed.

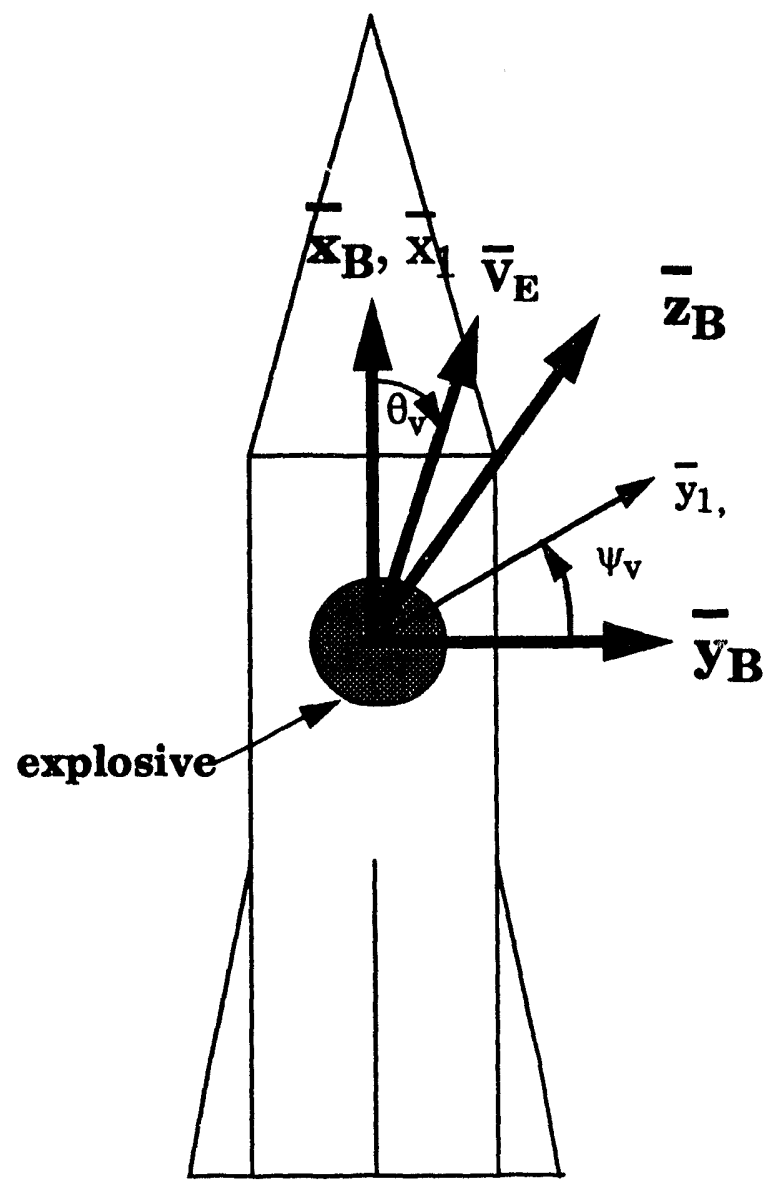

Figure 2.4: Explosive Velocity Vector Relative to the Body Reference Frame

\subsection{Fragment Trajectory Initial Conditions}

The initial conditions of each fragment trajectory are determined by adding the fragment's explosive velocity $\left(\bar{V}_{O}\right)$ to the missile's velocity $\left(\bar{V}_{M}\right)$ at the time and location of the explosion. The magnitude of the fragment's explosive velocity $\left(V_{0}\right)$ is 
an input parameter to SAFETIE and can be obtained using the Gurney formula shown in Eq 2.3. The direction of the velocity vector is obtained from a random sampling on its yaw and pitch angles ( $\psi_{\mathrm{v}}$ and $\theta_{\mathrm{v}}$ respectively). These angles are defined with respect to the body reference frame (xyz). As illustrated in Figure 2.4. $\psi_{\mathrm{v}}$ is defined in the yz plane with the right hand rule (RHR). A rotation of $\psi_{\mathrm{v}}$ defines an intermediate axis $(x y z)_{1}$. The explosive velocity reference frame $(x y z)_{v}$ is defined by a rotation of $\theta_{v}$ in the $x_{1} z_{1}$ plane, again defined with the RHR. The explosive velocity vector $\bar{V}_{E}$ is defined along the $\mathrm{x}_{\mathrm{v}}$ axis. The explosive velocity components in the body reference frame $\left(u_{E}, v_{E}, w_{E}\right)$ due to the premature detonation of the $\mathrm{HE}$ are given by

$$
\left[\begin{array}{c}
u \\
v \\
w
\end{array}\right]_{E}=V_{E}\left[\begin{array}{c}
\cos \theta_{v} \\
\sin \theta_{v} \sin \psi_{v} \\
-\sin \theta_{v} \cos \psi_{v}
\end{array}\right]
$$

SAFETIE1 was written so that minimum and maximum values on $\psi_{\mathrm{v}}$ and $\theta_{\mathrm{v}}$ can be specified by users. This allows them to investigate fragment impacts from only certain parts of the payload. Both the missile's velocity and the fragment's explosive velocity are converted to their geodetic components and then added. The three geodetic components are converted to total velocity magnitude $\left(V_{T}\right)$ and the two flight path angles ( $\sigma$ and $\gamma$ ) for the AMEER input file. Reference 7 contains a detailed description of the conversion process. The position information of altitude, latitude, and longitude required by SAFETIE is already in the proper form for AMEER.

Results from using this option in SAFETIE for the ZEST experiment are available in References 1 and 2 and are briefly summarized here. The casualty expectations $\left(E_{C}\right)$ is given by

$$
E_{C}=P_{I} \bar{N} \frac{A_{P}}{A_{X}}
$$

where $\bar{N}$ is the average number of fragments per explosion in the exclusion area, $A_{P}$ is the area taken up by the population (about 32 square feet per person) and $A_{X}$ is the exclusion area in square feet. The casualty expectations for Kauai and the neighboring islands are given by Table 1.1. 
Table 1.1: ZEST Casualty Expectations

\begin{tabular}{|l|l|l|c|c|}
\hline \multicolumn{1}{|c|}{ Area } & \multicolumn{1}{|c|}{$\overline{\mathbf{N}}$} & \multicolumn{1}{c|}{$\mathrm{P}_{\mathbf{I} / \mathrm{PD}}$} & $\mathrm{P}_{\mathbf{I}}$ & $\mathrm{C}_{\mathrm{E}}$ \\
\hline \hline Kauai & 38.4 & 0.525 & $5.356 \times 10^{-5}$ & $1.179 \times 10^{-9}$ \\
\hline Niihau & 2.0 & 0.092 & $1.335 \times 10^{-5}$ & $2.612 \times 10^{-11}$ \\
\hline Oahu & 1.4 & 0.256 & $3.840 \times 10^{-5}$ & $4.136 \times 10^{-8}$ \\
\hline Total & 13.3 & 0.873 & $1.053 \times 10^{-5}$ & $4.136 \times 10^{-8}$ \\
\hline
\end{tabular}




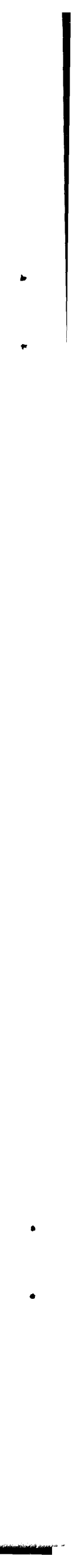




\section{The Missile Breakup Debris Model}

SNL was asked by Kwajalein Missile Range (KMR) to assess the mission hazard due to potential debris impact in the Marshall Islands area for the STARS Mission 1 (known as STARS M1). STARS M1 carried two SDIO payloads from the Kauai Test Facility (KTF) to the Marshall Islands area. The terminal portions of the payload trajectories were observed from various sensor platforms on the Kwajalein Atoll and the surrounding area. Primary flight safety responsibility for the mission is assigned to the Naval Air Warfare Center (NAWC), Weapons Division, with cooperation of the Pacific Missile Range Facility (PMRF) and the Kwajalein Missile Range (KMR). Sandia National Laboratories was tasked to provide supporting data and analysis, as requested by the ranges. As a result of this request, a methodology for investigating true probabilistic hazard assessments for rocket missions in which the vehicle is purposely destroyed had to be established. Basically, the methodology had to model some kind of prescribed failure (in a probabilistic manner) of the STARS third stage, account for some reaction time to that failure for the mission flight safety officer (MFSO) to activate the FTS, and then compute impact locations of the debris caused by FTS activation. Other concerns, such as probabilistic modeling of the off-nominal trajectories, probabilistic wind models, and further debris breakup, were to be included in the methodology. The intent was to estimate upper bounds for expected casualty rates and impact probability for the Marshall Islands areas which adjoin the STARS M1 instantaneous impact point (IIP) ground track (see Figure 3.1).

The analysis was divided into two distinct trajectory calculations. The first part modeled the particular tumble turn failure that could caused the trajectory to deviate. The nozzle gimbal angle going to its physical limits (hard over) or the nozzle gimbal angle becoming fixed (stuck or frozen nozzle gimbal) were two examples of the types of failures considered. Deviations of position and velocity from the nominal trajectory were modeled in a covariance matrix. ${ }^{5,8} \mathrm{~A}$ trajectory simulation is used that repeatedly models each failure mode (using the MCPRAM code) at one second intervals only along that portion of the trajectory where the debris was potentially hazardous. Specific parameters were varied either systematically or randomly (in a Monte (arlo sense) in order to build up a data base correlating failures to the vehicle state vector at FTS activation. For the STARS M1 analysis, nothing was investigated prior to 18 seconds after the third stage ignition because debris could not reach any inhabitable island. The state vector consisted of time, position, velocity, body orientation, and angular velocity. Position was defined by altitude, latitude, and longitude; velocity was defined by the magnitude of geodetic velocity and the horizontal and vertical flight path angles; body orientation was defined by three geodetic-to-body Euler angles; and the angular velocity was defined by the bodyreferenced angular rates $p, q$, and $r$. The delay time between the start of the failure simulation and the activation of FTS was used to simulate the response time of the 
MFSO. The STARS M1 analysis assumed two delay times of three and four seconds between failure and FTS activation (per instruction from KMR). At FTS activation, SAFETIE was used to generate impact locations for the resulting fragments. This SAFETIE option required that the user specify each fragment size, shape, and incremental velocity model. Casualty expectation were computed in PDF based on impact locations, specific failure probabilities, and local demographics.

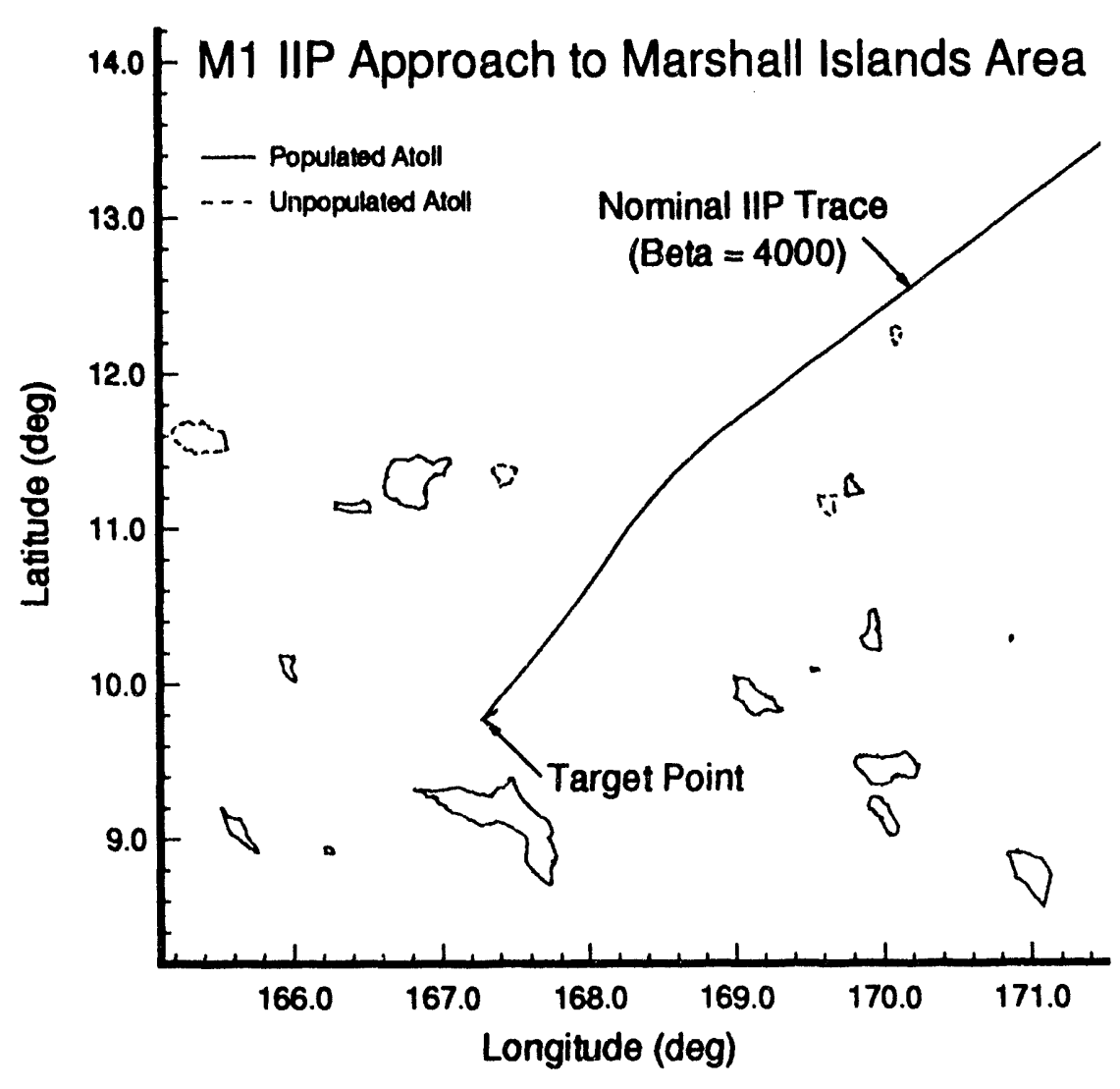

Figure 3.1: STARS M1 Approaching Kwajalein

\subsection{Fragment Description}

In this breakup option, SAFETIE users are responsible for providing information about each fragment's mass, shape, and incremental velocity model. Shape information includes a reference area and a file containing the drag model (in AMEER format) for each fragment. AMEER is extremely versatile in allowing for drag to be a function of any legal variable, such as Mach number, angle of attack, Reynold's number, altitude, and so on. The incremental velocity model, though not as 
versatile, is very realistic. The model assumes that the fragments are thrown in the direction that they are pointing relative to the FTS action. Items forward of the action are thrown forward; items rearward are thrown rearward; and items to the side are thrown to the side. The user-defined velocity roll angle $\phi_{\mathrm{V}}$ determines the direction of the incremental velocity $(\Delta V)$. If $\left|\phi_{\mathrm{V}}\right|<360^{\circ}$, then the velocity is to the side (Fig 3.2), and the incremental velocity is in the yz plane of the AMEER body reference frame, $(x y z)_{B}$. If $\phi_{V}>360^{\circ}$, then the velocity is defined only on the $x_{B}$ vector in the positive (forward) direction. If $\phi_{\mathrm{V}}<-360^{\circ}$, then the velocity is in the negative (rearward) direction.

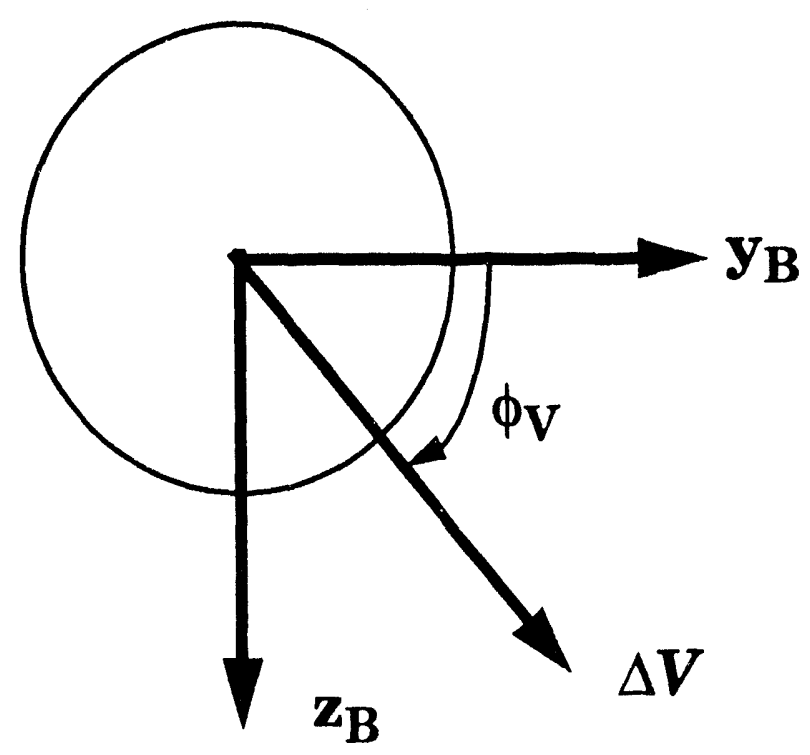

Figure 3.2: Incremental Velocity Relative to the Body Reference Frame

The magnitude of the incremental velocity is assumed to have a normal distribution and to be a tabular function of time. Users are free to determine the length of each table, which defines the mean of the incremental velocity at discrete values of time. The stand ard deviation is assumed to be a user-defined percentage of the mean incremental velocity or a constant value. Since some types of failures (such as the hard over nozzle) can produce significant angular rates, users have the option of adding in the velocity due to the angular rates. If this option is chosen, the $\mathrm{cg}$ of the body (as a tabular function of stage time) and the cg location of each fragment must be defined. SAFETIE also allows users to define a breakup altitude at which the original fragments breakup into smaller fragments (perhaps due to aerothermal demise).

The complete hazard analysis for the STARS M1, documented in Reference 3, is useful for showing how some of these options work. Some of the highlights from that 
analysis are summarized next.

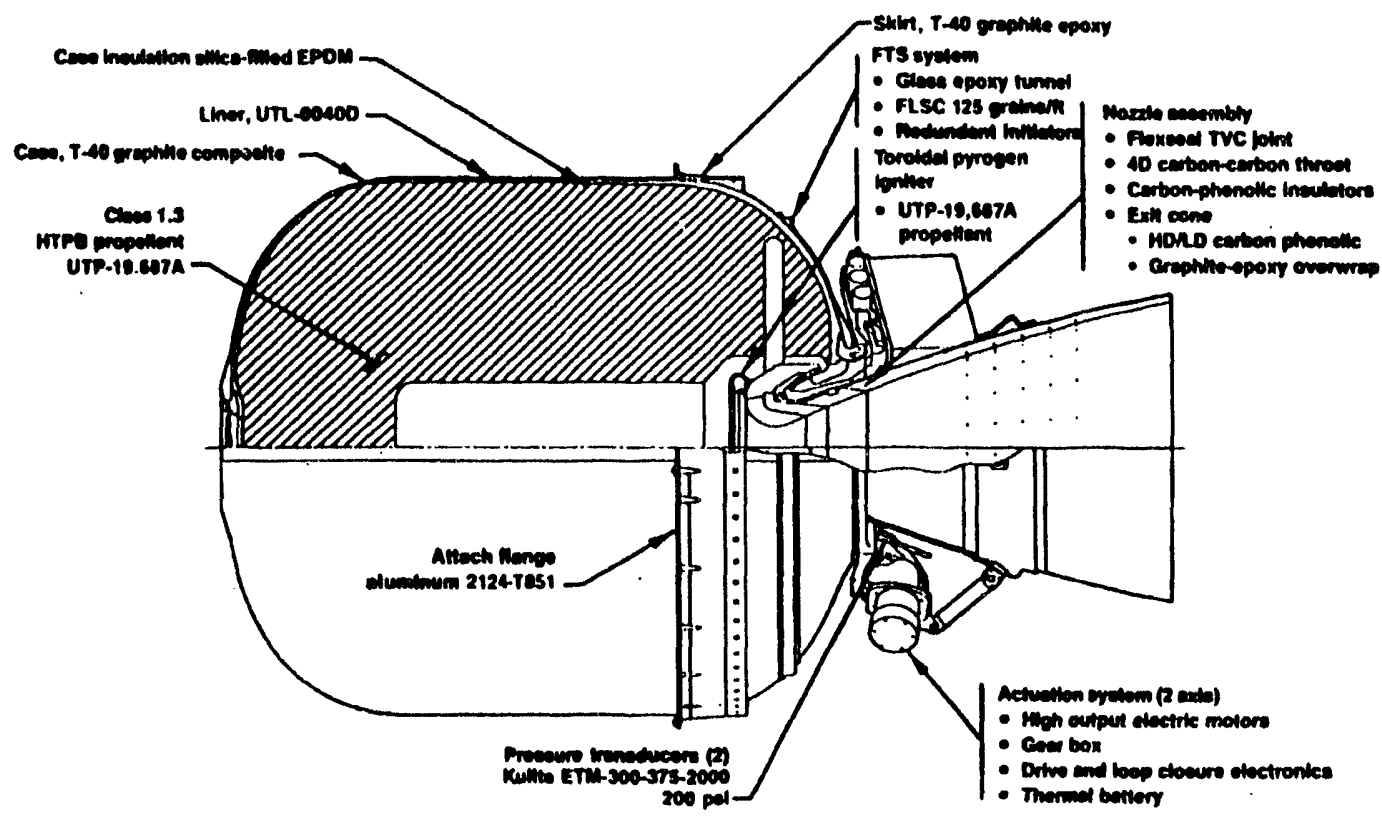

Figure 3.3: The Orbus 1 STARS Third Stage Motor

\subsection{Summary of STARS M1 Results}

A mission hazard assessment For STARS M1 in the Marshall Island area was conducted by the Flight Dynamics Department at SNL. The STARS vehicle consists of three stages, of which the first two stages are derived from retired Polaris A3 fleet ballistic missile assets. Since only the third stage and its payloads reach the Marshall Islands area, the first two stages were not considered in the hazard assessment. The third stage is an all new Sandia design, added to meet the objectives of the program. The STARS Orbus 1 third stage motor, shown in Figure 3.3 was designed and built to Sandia specifications by the Chemical Systems Division of United Technologies Corporation.

The assessment began with a failure mode analysis to determine which component failures could cause a significant deviation in the trajectory. Next, the nature of the trajectory deviation resulting from each specific component failure was identified, permitting the effects of some failure modes to be combined. For example, the third stage nozzle might become fixed in a given position due either to some sort of mechanical failure or to a faulty electrical signal; the effect on the trajectory would be the same in either case. Finally, some underlying assumptions, conservative in nature, were made in order to complete the analysis in a timely and cost-effective manner. For example, a large number of fragments were assumed to reach the earth. 
It was far more likely that some of the smaller fragments would fully demise due to aerothermal heating. Furthermore, the drag profiles assumed for the fragments were modeled much smaller than ordinarily would be the case. Consequently, all fragments were assumed to have sufficient impact kinetic energy to pose a safety problem. For this analysis, seven fragments were assumed to be formed from the FTS activation. Table 3.1 describes these fragments and there associated incremental velocity tables.

Table 3.1: Fragment Velocities due to FTS Activation During Third Stage Burn

\begin{tabular}{|c|c|c|c|c|c|c|c|}
\hline \multirow[t]{2}{*}{$\begin{array}{c}\text { Item } \\
\text { Number }\end{array}$} & \multirow[t]{2}{*}{$\begin{array}{l}\text { Fragment } \\
\text { Description }\end{array}$} & \multirow{2}{*}{$\begin{array}{c}\text { Number } \\
\text { of } \\
\text { Pieces }\end{array}$} & \multicolumn{4}{|c|}{$\begin{array}{l}\text { Mean Incremental Velocity } \\
\text { (ft/sec) } \\
\text { for stage time values off }\end{array}$} & \multirow{2}{*}{$\begin{array}{l}\text { Standard } \\
\text { Deviation } \\
\text { of Velocity }\end{array}$} \\
\hline & & & $2 \mathrm{sec}$ & $22 \mathrm{sec}$ & $31 \mathrm{sec}$ & $38 \mathrm{sec}$ & \\
\hline 1 & $\begin{array}{l}\text { Thrust Vector } \\
\text { Actuator }\end{array}$ & 2 & 20 & 74 & 78 & 53 & $15 \%$ \\
\hline 2 & $\begin{array}{l}\text { TVCElectronics } \\
\text { Package }\end{array}$ & 1 & 20 & 74 & 78 & 53 & $15 \%$ \\
\hline 3 & $\begin{array}{l}\text { Motor Aft Dome } \\
\text { and Nozzle }\end{array}$ & 1 & 20 & 74 & 78 & 53 & $15 \%$ \\
\hline 4 & Payload & 2 & 8 & 16 & 19 & 17 & $4 \mathrm{ft} / \mathrm{sec}$ \\
\hline 5 & $\begin{array}{l}\text { Third Stage } \\
\text { Booster }\end{array}$ & 1 & 8 & 16 & 19 & 17 & $3 \mathrm{ft} / \mathrm{sec}$ \\
\hline
\end{tabular}

These seven were then assumed to breakup into 19 fragments classes at 150,000 feet altitude. They are called fragment classes because each impact could be representative of more than one fragment. This was done simply to reduce the total number of trajectories that had to be computed. Table 3.2 shows these nineteen classes.

The four failure modes investigated were hard-over nozzle, stuck nozzle, return to null position nozzle, and instantaneous destruct. For each of the first three failure modes, 151 Monte Carlo trajectories were computed at each second between 18 seconds and 38 seconds after the third stage ignition, corresponding to 3171 SAFETIE initial conditions per failure. Since the analysis was conducted for MFSO response times of both three and four seconds, each of the first three failure mode required 120,498 trajectories (3171 initial conditions x 19 fragments $\times 2$ response times). The fourth required only 60,249 trajectories, since the "response time" was 
Table 3.2: Fragment Classes Which Impact the Earth's Surface

\begin{tabular}{|c|c|c|c|c|}
\hline $\begin{array}{c}\text { Class } \\
\text { ID }\end{array}$ & Description & $\begin{array}{c}\text { Quantit } \\
\mathrm{y}\end{array}$ & $\begin{array}{c}\text { Approximate } \\
\text { Mass } \\
\left(\mathrm{lb}_{\mathrm{m}}\right)\end{array}$ & $\begin{array}{c}\text { Approximate } \\
\text { Beta } \\
\left(\mathrm{lb} / \mathrm{ft}^{2}\right)\end{array}$ \\
\hline 1 & $\begin{array}{l}\text { nozzle, aft dome of Orbus } \\
\text { motor }\end{array}$ & 1 & 54.2 & 50 \\
\hline 2 & third stage skin (ring) & 1 & 46.9 & $6-13$ \\
\hline 3 & $\begin{array}{l}\text { dodecagon with compo- } \\
\text { nents }\end{array}$ & 10 & $1.0-287$ & $41-78$ \\
\hline 4 & spent Orbus motor & 1 & 109.4 & $10-19$ \\
\hline 5 & T. O. 1 mid module & 1 & 44 & $80-500$ \\
\hline 6 & T. O. 1 NTP & 1 & $20-30$ & $100-800$ \\
\hline 7 & T. O. 1 shell fragment & 100 & $\begin{array}{l}\text { avg: } 0.3 \\
\max : 1.0\end{array}$ & 5 \\
\hline 8 & T. O. 1 structure fragment & 1 & 2 & 10 \\
\hline 9 & T. O. 1 structure fragment & 2 & 4 & 20 \\
\hline 10 & T. O. 1 structure fragment & 1 & 5 & 40 \\
\hline 11 & T. 0.2 module & 1 & $45-120$ & 400 \\
\hline 12 & T. 0.2 module & 1 & $45-120$ & 350 \\
\hline 13 & T. 0.2 module & 1 & 70 & 70 \\
\hline 14 & T. O. 2 NTP & 1 & $20-30$ & $100-800$ \\
\hline 15 & T. 0.2 debris & 10 & $0.1-1.0$ & 3 \\
\hline 16 & T. O. 2 debris & 10 & $0.1-1.0$ & 5 \\
\hline 17 & yaw TVC actuator & 1 & 7 & $27-71$ \\
\hline 18 & pitch TVC actuator & 1 & 7 & $27-71$ \\
\hline 19 & TVC electronics box & 1 & 9.5 & $16-43$ \\
\hline
\end{tabular}

zero. Figures 3.4 through 3.6 show the impacts generated by the four seconds delay model. This information, along with the instantaneous destruct information (Figure 3.7), and the nominal flight debris impact information, was used to produce the probability density contours in Figure 3.8. Table 3.3 contains a summary of the 
casualty expectations computed for STARS M1. Note that all casualty expectations were below the accepted value of $1.0 \times 10^{-9}$.

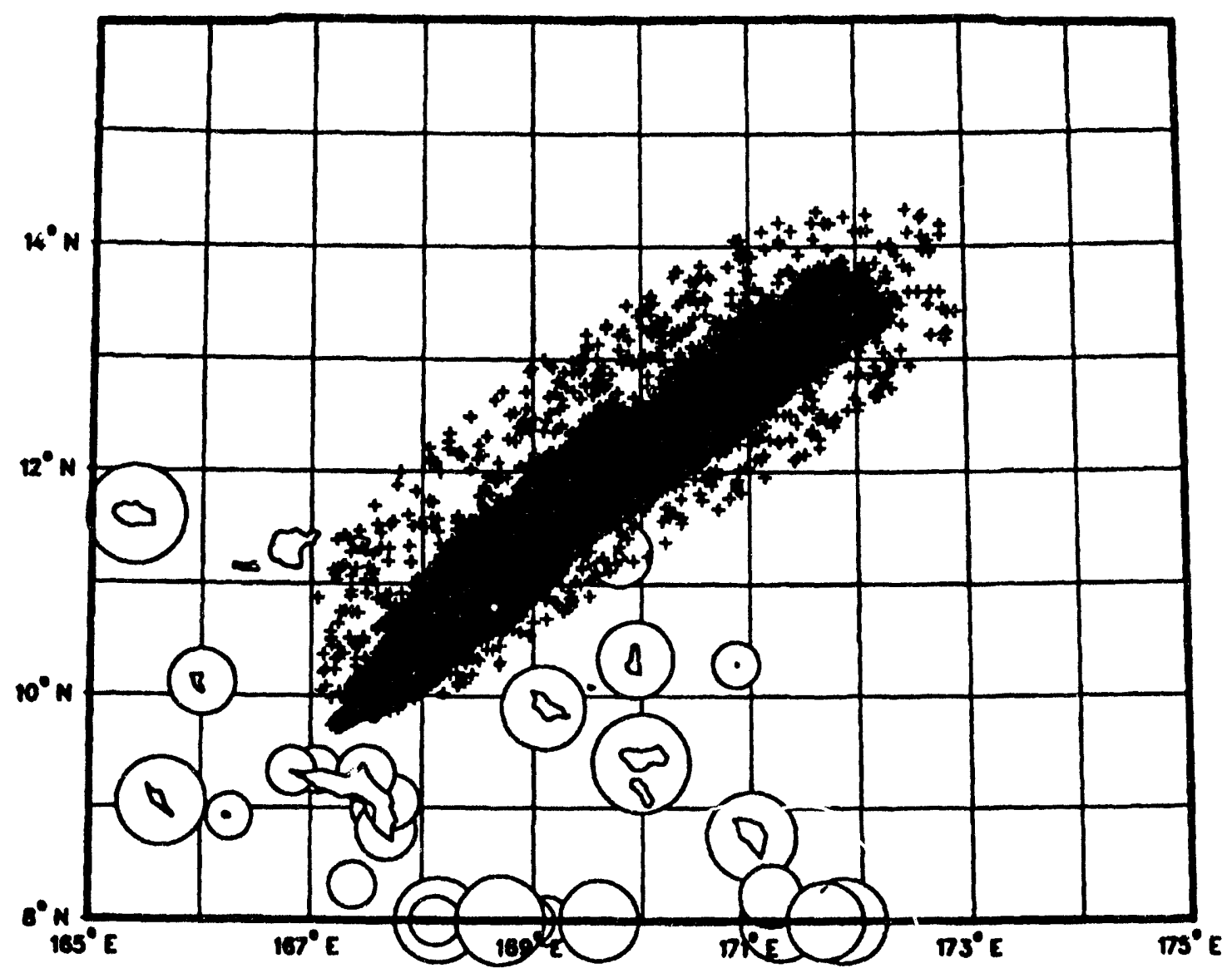

Figure 3.4: Debris Impacts for STARS M1 Hard Over Nozzle Failure Mode with Four Second Delay 


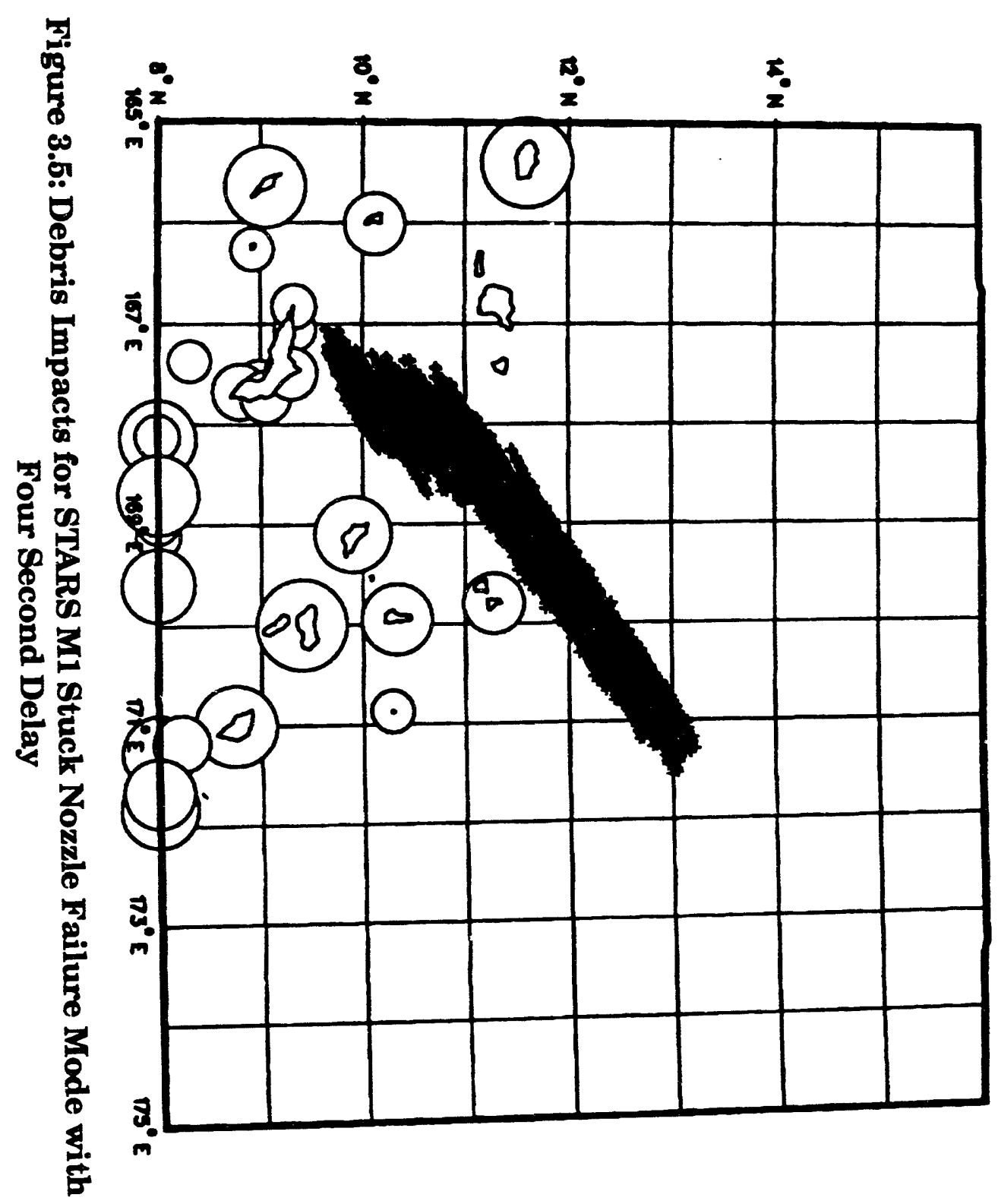




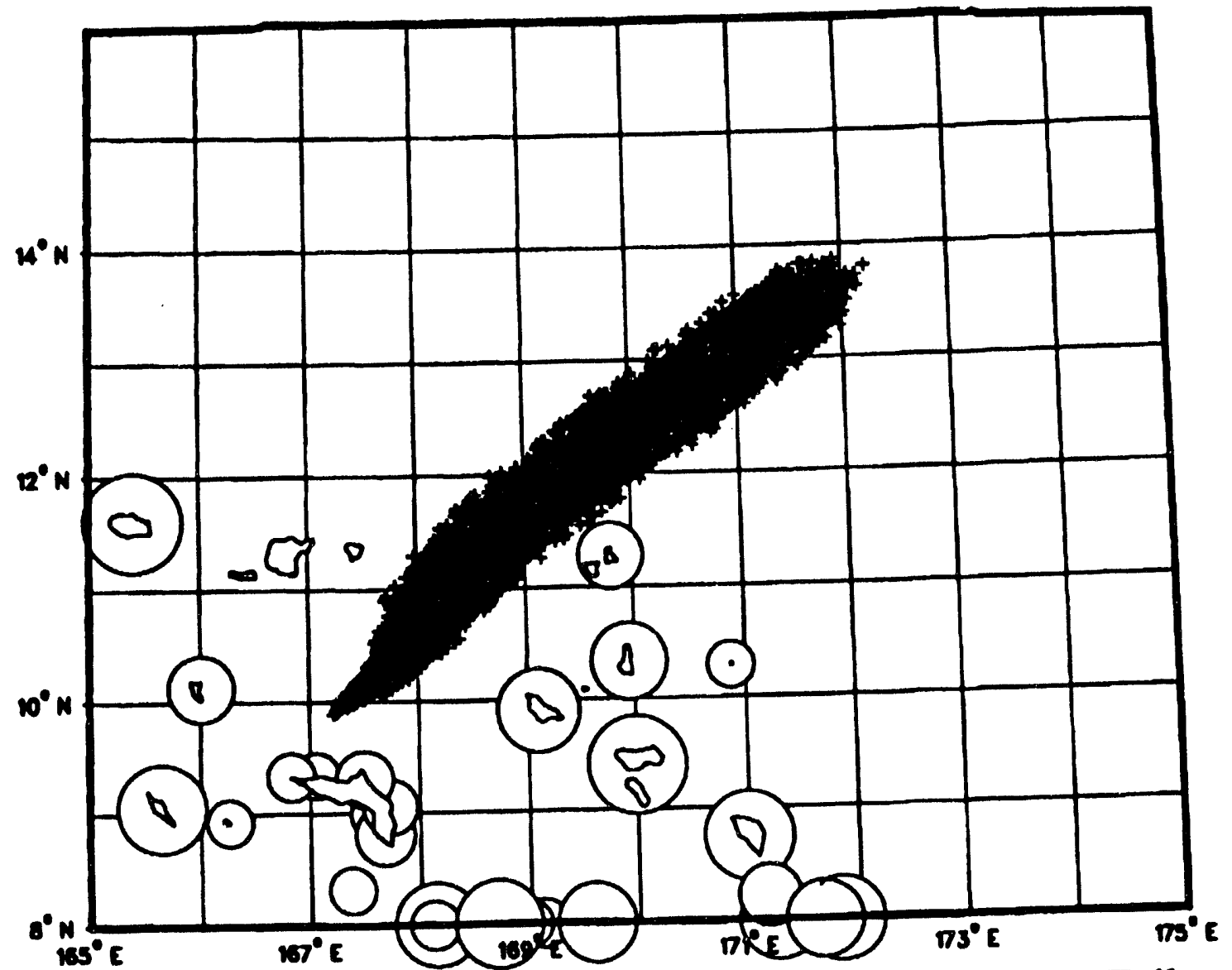

Figure 3.6: Debris Impacts for STARS M1 Null Position Nozzle Failure Mode with Four Second Delay 


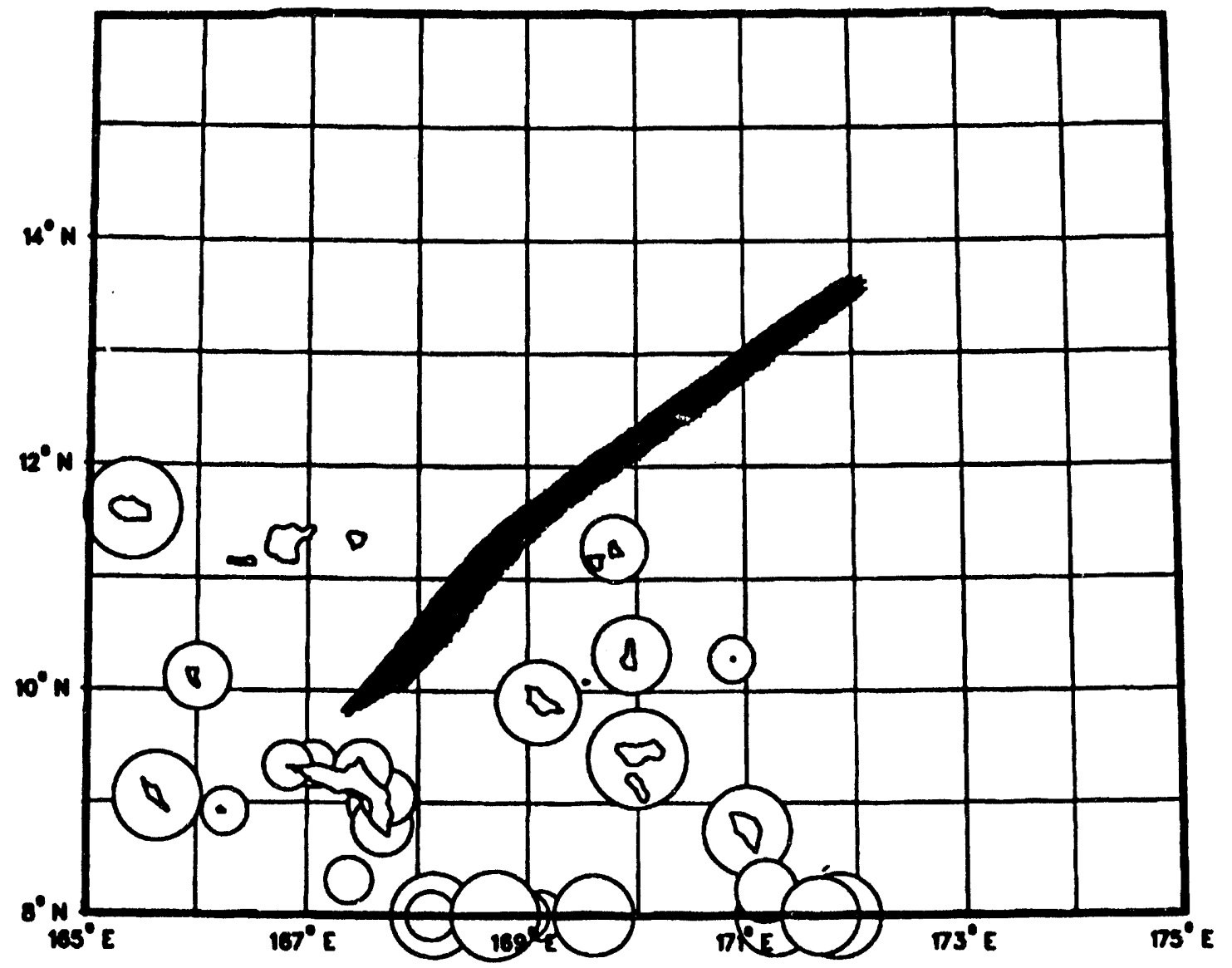

Figure 3.7: Debris Impacts for STARS M1 Instantaneous Destruct Failure Mode with Four Second Delay 


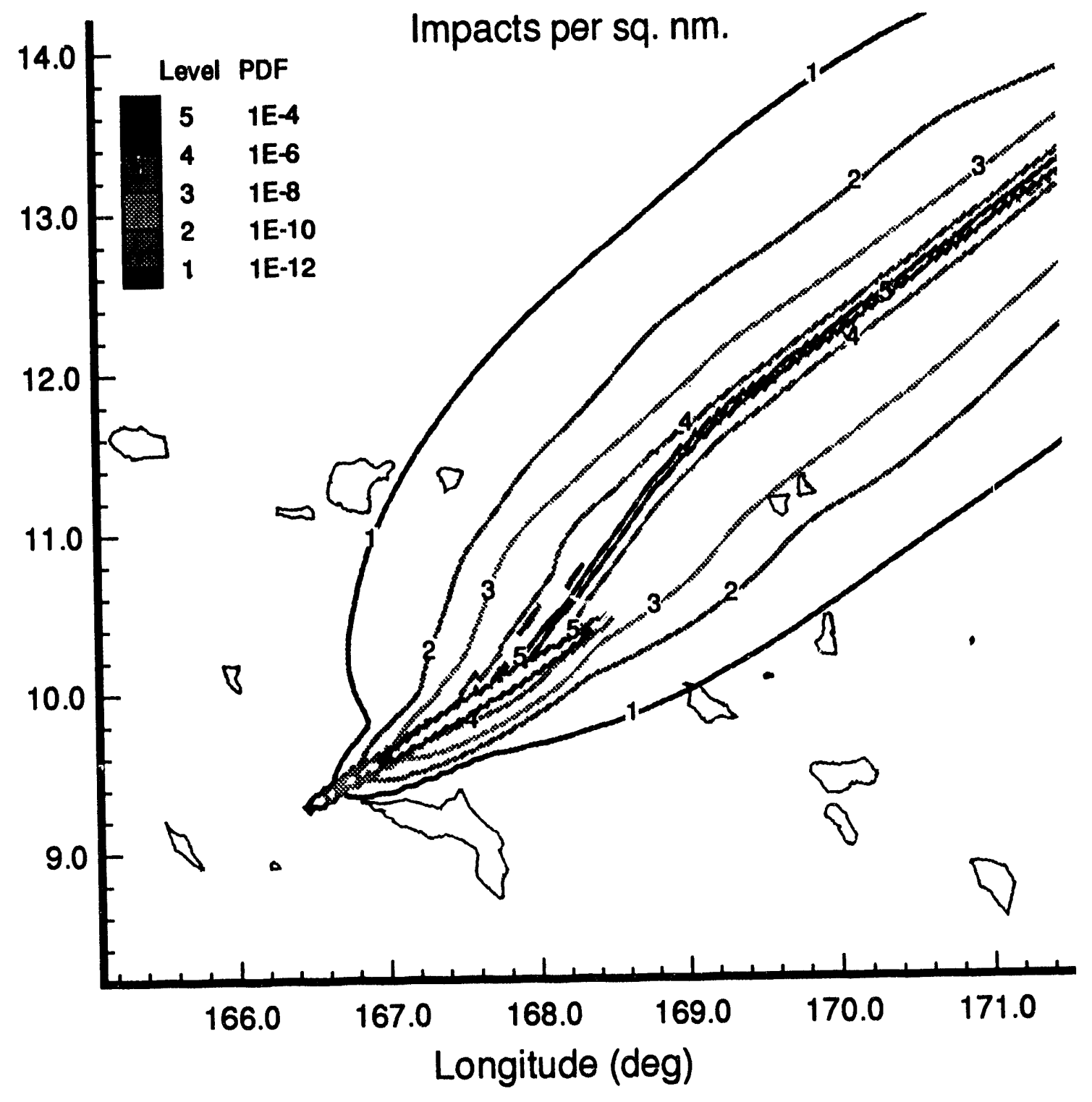

Figure 3.8: STARS M1 Probability Density Contours for Four Second Delay 
Table 3.3: Land Impact Probabilities and Expected Casualties: 4 Second FTS Delay

\begin{tabular}{|c|c|c|c|c|c|c|}
\hline \multirow{2}{*}{ Name } & Land Area & N. Lat & E. Long & \multirow{2}{*}{ Population } & \multirow{2}{*}{$\begin{array}{l}\text { Land Impact } \\
\text { Probability }\end{array}$} & \multirow{2}{*}{$\begin{array}{l}\text { Expected } \\
\text { Casualties }\end{array}$} \\
\hline & sq. $\mathrm{nm}$. & deg. & deg. & & & \\
\hline \multicolumn{7}{|c|}{ Ailinginae Atoll } \\
\hline Majokoryaan & 0.118 & 11.1320 & 166.5270 & 0 & $4.64495 \times 10^{-15}$ & 0 \\
\hline \multicolumn{7}{|l|}{ Bikar Atoll } \\
\hline Bikar & 0.065 & 12.1862 & 170.1033 & 0 & $1.24507 \times 10^{-07}$ & 0 \\
\hline \multicolumn{7}{|l|}{ Bikini Atoll } \\
\hline Bikini & 0.632 & 11.6277 & 165.5458 & 0 & $2.48726 \times 10^{-19}$ & 0 \\
\hline \multicolumn{7}{|l|}{ Ailuk Atoll } \\
\hline Ailuk & 0.204 & 10.217 & 169.982 & 465 & $9.39821 \times 10^{-15}$ & $1.8568 \times 10^{-17}$ \\
\hline Enijabro & 0.145 & 10.4504 & 169.9563 & 3 & $7.13436 \times 10^{-14}$ & $1.2794 \times 10^{-18}$ \\
\hline Kapen & 0.223 & 10.4588 & 169.9500 & 4 & $1.22214 \times 10^{-13}$ & $1.90009 \times 10^{-18}$ \\
\hline \multicolumn{7}{|l|}{ Erikub Atoll } \\
\hline Erikub & 0.136 & 9.0200 & 170.0616 & 0 & $1.15955 \times 10^{-21}$ & $\overline{0}$ \\
\hline \multicolumn{7}{|c|}{ Kwajalein Atoll } \\
\hline Big Bustard & 0.009 & 8.762 & 167.739 & 7 & $1.09904 \times 10^{-20}$ & $7.40914 \times 10^{-24}$ \\
\hline Biggerann & 0.152 & 9.337 & 167.060 & 12 & $1.4435 \times 10^{-15}$ & $9.87765 \times 10^{-20}$ \\
\hline Ebadon & 0.350 & 9.328 & 166.827 & 38 & $1.54692 \times 10^{-15}$ & $1.45573 \times 10^{-19}$ \\
\hline Ebeye & 0.088 & 8.780 & 167.739 & 8500 & $1.45166 \times 10^{-19}$ & $1.21535 \times 10^{-20}$ \\
\hline Ebioaji & 0.023 & 8.836 & 167.740 & 10 & $9.6809 \times 10^{-20}$ & $3.64826 \times 10^{-23}$ \\
\hline Eniwetak & 0.018 & 9.017 & 167.716 & 4 & $1.58222 \times 10^{-18}$ & $3.04755 \times 10^{-22}$ \\
\hline Ennubirr & 0.038 & 9.366 & 167.496 & 380 & $8.24113 \times 10^{-16}$ & $7.14307 \times 10^{-18}$ \\
\hline Ennylabegan & 0.155 & 8.799 & 167.618 & 98 & $4.12272 \times 10^{-19}$ & $2.25931 \times 10^{-22}$ \\
\hline Enubuj & 0.105 & 8.749 & 167.685 & 60 & $1.1132 \times 10^{-19}$ & $5.51358 \times 10^{-23}$ \\
\hline Gagan & 0.009 & 9.288 & 167.538 & 8 & $6.03562 \times 10^{-17}$ & $4.65016 \times 10^{-20}$ \\
\hline
\end{tabular}


Table 3.3: Land Impact Probabilities and Expected Casualties: 4 Second FTS Delay

\begin{tabular}{|c|c|c|c|c|c|c|}
\hline \multirow{2}{*}{ Name } & Land Area & N. Lat & E. Long & \multirow{2}{*}{ Population } & \multirow{2}{*}{$\begin{array}{l}\text { Land Impact } \\
\text { Probability }\end{array}$} & \multirow{2}{*}{$\begin{array}{l}\text { Expected } \\
\text { Casualties }\end{array}$} \\
\hline & sq. $\mathrm{nm}$. & deg. & deg. & & & \\
\hline Gellinam & 0.009 & 9.099 & 167.729 & 6 & $2.90493 \times 10^{-18}$ & $1.67858 \times 10^{-21}$ \\
\hline Gugeegue & 0.073 & 8.849 & 167.744 & 10 & $3.79718 \times 10^{-19}$ & $4.50854 \times 10^{-23}$ \\
\hline Kwajalein & 0.948 & 8.723 & 167.737 & 3446 & $6.06719 \times 10^{-19}$ & $1.91158 \times 10^{-21}$ \\
\hline Legan & 0.035 & 8.984 & 167.579 & 6 & $2.08464 \times 10^{-18}$ & $3.0975 \times 10^{-22}$ \\
\hline $\begin{array}{c}\text { Little } \\
\text { Bustard }\end{array}$ & 0.003 & 8.755 & 167.737 & 5 & $3.26939 \times 10^{-21}$ & $4.72295 \times 10^{-24}$ \\
\hline Meck & 0.047 & 9.003 & 167.727 & 255 & $3.23794 \times 10^{-18}$ & $1.52268 \times 10^{-20}$ \\
\hline Omelek & 0.012 & 9.050 & 167.743 & 1 & $1.73415 \times 10^{-18}$ & $1.25257 \times 10^{-22}$ \\
\hline Roi-Namur & 0.510 & 9.396 & 167.476 & 470 & $1.75154 \times 10^{-14}$ & $1.39909 \times 10^{-17}$ \\
\hline \multicolumn{7}{|l|}{ Lae Atoll } \\
\hline Lae & 0.230 & 8.921 & 166.264 & 192 & $4.45395 \times 10^{-19}$ & $3.22267 \times 10^{-22}$ \\
\hline Lib Island & 0.230 & 8.3160 & 167.3800 & 140 & $2.75686 \times 10^{-22}$ & $1.4545 \times 10^{-25}$ \\
\hline \multicolumn{7}{|l|}{ Likiep Atoll } \\
\hline Jibal & 0.156 & 9.888 & 169.276 & 70 & $1.02418 \times 10^{-14}$ & $3.98335 \times 10^{-18}$ \\
\hline Lado & 0.189 & 9.8425 & 169.3105 & 20 & $5.93128 \times 10^{-15}$ & $5.4402 \times 10^{-19}$ \\
\hline Likeip & 0.510 & 9.823 & 169.303 & 406 & $1.31156 \times 10^{-14}$ & $9.04988 \times 10^{-18}$ \\
\hline Mato & 0.461 & 10.044 & 168.997 & 30 & $7.4375 \times 10^{-13}$ & $4.19513 \times 10^{-17}$ \\
\hline Mero & 0.148 & 9.895 & 169.265 & 60 & $1.12102 \times 10^{-14}$ & $3.93913 \times 10^{-18}$ \\
\hline \multicolumn{7}{|c|}{ Maleolap Atoll } \\
\hline Airik & 0.204 & 8.5033 & 171.1980 & 220 & $2.98603 \times 10^{-29}$ & $2.79116 \times 10^{-32}$ \\
\hline Kaven & 0.612 & 8.8983 & 170.8460 & 95 & $2.24421 \times 10^{-24}$ & $3.01948 \times 10^{-28}$ \\
\hline Ollot & 0.102 & 8.7708 & 171.1810 & 80 & $2.17078 \times 10^{-27}$ & $1.47572 \times 10^{-30}$ \\
\hline Tar & 0.081 & 8.8383 & 171.0967 & 29 & $1.19615 \times 10^{-26}$ & $3.71189 \times 10^{-30}$ \\
\hline Tjan & 0.102 & 8.9075 & 170.8950 & 0 & $2.85303 \times 10^{-25}$ & 0 \\
\hline
\end{tabular}


Table 3.3: Land Impact Probabilities and Expected Casualties: 4 Second FTS Delay

\begin{tabular}{|c|c|c|c|c|c|c|}
\hline \multirow{2}{*}{ Name } & Land Area & N. Lat & E. Long & \multirow{2}{*}{ Population } & \multirow{2}{*}{$\begin{array}{l}\text { Land Impact } \\
\text { Probability }\end{array}$} & \multirow{2}{*}{$\begin{array}{l}\text { Bxpected } \\
\text { Casualties }\end{array}$} \\
\hline & sq. nm. & deg. & deg. & & & \\
\hline Mejit Island & 0.642 & 10.284 & 170.870 & 320 & $2.55216 \times 10^{-16}$ & $1.10261 \times 10^{-19}$ \\
\hline Rongelap & 0.788 & 11.157 & 166.871 & 165 & $3.40495 \times 10^{-13}$ & $6.17968 \times 10^{-17}$ \\
\hline Ujae & 0.394 & 8.930 & 165.761 & 209 & $7.59224 \times 10^{-20}$ & $3.49075 \times 10^{-23}$ \\
\hline Utirik & 1.283 & 11.226 & 169.852 & 256 & $1.19955 \times 10^{-09}$ & $2.07457 \times 10^{-13}$ \\
\hline Wotho & 0.875 & 10.169 & 166.011 & 89 & $2.89305 \times 10^{-15}$ & $2.55057 \times 10^{-19}$ \\
\hline \multicolumn{7}{|l|}{ Wotje Atoll } \\
\hline Ormed & 0.254 & 9.554 & 170.151 & 210 & $1.84487 \times 10^{-18}$ & $1.32205 \times 10^{-21}$ \\
\hline Wotje & 0.718 & 9.457 & 170.241 & 252 & $8.46544 \times 10^{-19}$ & $2.57527 \times 10^{-22}$ \\
\hline
\end{tabular}




\section{Vehicle Impact Debris Breakup Model}

The Strategic Defense Initiative Organization (SDIO) is developing kinetic energy interceptors for destroying incoming reentry vehicles and missiles. The Lightweight ExoAtmospheric Interceptor (LEAP) Program is a part of this SDIO effort. When an inbound hostile vehicle is detected, a LEAP interceptor is to be boosted to a point in space from which its onboard guidance and tracking system can control lateral thrusters to place the LEAP directly in the path of the oncoming vehicle. The relative kinetic energy resulting from the velocity difference between the interceptor and incoming vehicle velocity is intended to destroy both vehicles. A series of flight tests had been planned to support the development of the LEAP interceptor technology at the Army White Sands Missile Range (WSMR). The first tests had low relative velocities between the interceptor and target vehicle of about $0.8 \mathrm{~km} / \mathrm{s}$. As the program would have progressed, the relative velocities between the target and interceptor would have increased to $2 \mathrm{~km} / \mathrm{s}$ and finally to $4 \mathrm{~km} / \mathrm{s}$. This would have require the use of a rocket system to launch the target and another to launch the interceptor.

When vehicles impact at relative velocities of 2 to $4 \mathrm{~km} / \mathrm{s}$, considerable debris can be generated. Since the intercepts are planned to occur at altitudes above $100 \mathrm{~km}$, the debris will have time to spread out over a large area before they encounter the atmosphere and begin decelerating. As the relative kinetic energy of the intercept increases, it has been observed that vehicles fragment more completely and the relative "spread" velocities imparted to the fragments increase. Hence, the ground footprint for the debris tends to increase with impact velocity. WSMR is responsible for insuring the safety of people and property both on and off of their range for any test in which they participate. SNL was tasked to characterize the debris that may be generated by high relative velocity LEAP intercept tests and to assess the magnitude of the hazard that they may represent to people on the ground and to aircraft flying through the area. Consequently, SAFETIE was modified to include the FAST $^{12,13}$ (Fragmentation Algorithms for Satellite Targets) set of equations, written by Kaman Sciences Corporation for the Defense Nuclear Agency (DNA).

\subsection{Debris Breakup Models}

FAST is an empirically-derived debris breakup model primarily designed to predict orbital debris as a result of hypervelocity impacts. There is little or no information as to whether it could be extended into the LEAP intercept regime with much lower closing velocities; however, it is the only type of model that can produce cost-effective solutions. The FAST debris model, as with the other two SAFETIE options, consists of computing mass, shape parameters, and a velocity vector for each fragment. FAST is presented in References 12 and 13 as a series of equations with an example of how to code them into a FORTRAN subroutine. Though this seemed a 
difficult way to evaluate a model, at least it could be quite readily implemented into SAFETIE. So that SAFETIE users can see the validity of the FAS'T model, comparisons will be made to IMPACT $\mathrm{v} 2.0$, another empirically-derived debris breakup model. IMPACT was written by the Aerospace Corporation for the USAF Space Systems Division. It was available only as an executable, PC-based code. IMPACT is a highly compartmentalized computer code and is very user friendly, with a windowing interface for describing the intercept conditions and choosing which option to run.

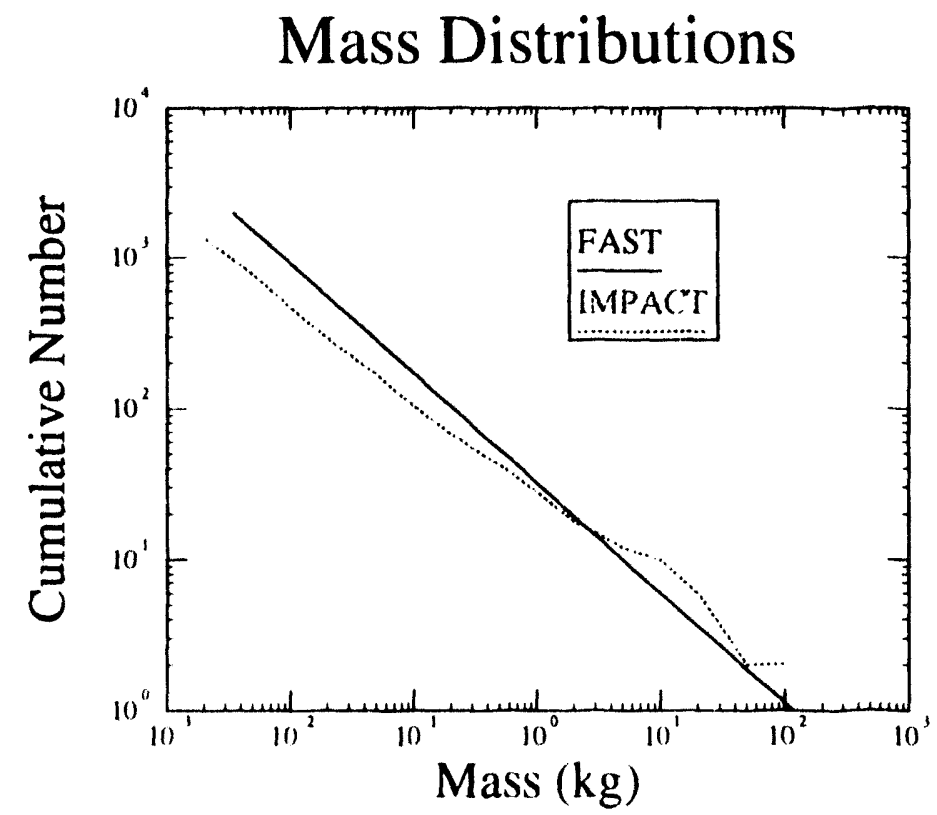

Figure 4.1: FAST and IMPACT Mass Distribution

\section{Mass Distribution Model}

Both FAST and IMPACT use a power law to model the mass distribution (Figure 5.1). This has the form:

$$
C N=a\left(\frac{m}{m_{t, t}}\right)^{-b}
$$

where:

$C N$ is the cumulative number (the number of fragments of size $m$ or larger),

$a$ and $b$ are empirical constants that depend on the impact conditions, and

$m_{t o t}$ and $m$ are the total mass and the fragment mass respectively.

Figure 4.1 illustrates the power law for the FAST and IMFACT models with LEAP intercept conditions. The erratic behavior of the IMPACT curve in the one $\mathrm{kg}$ range 
is the result of having only an executable version of IMPACT. The IMPACT curve was created from an output file which shows some number of fragments reduction features inherent in IMPACT, while the FAST curve was computed from an equation in Reference 13.

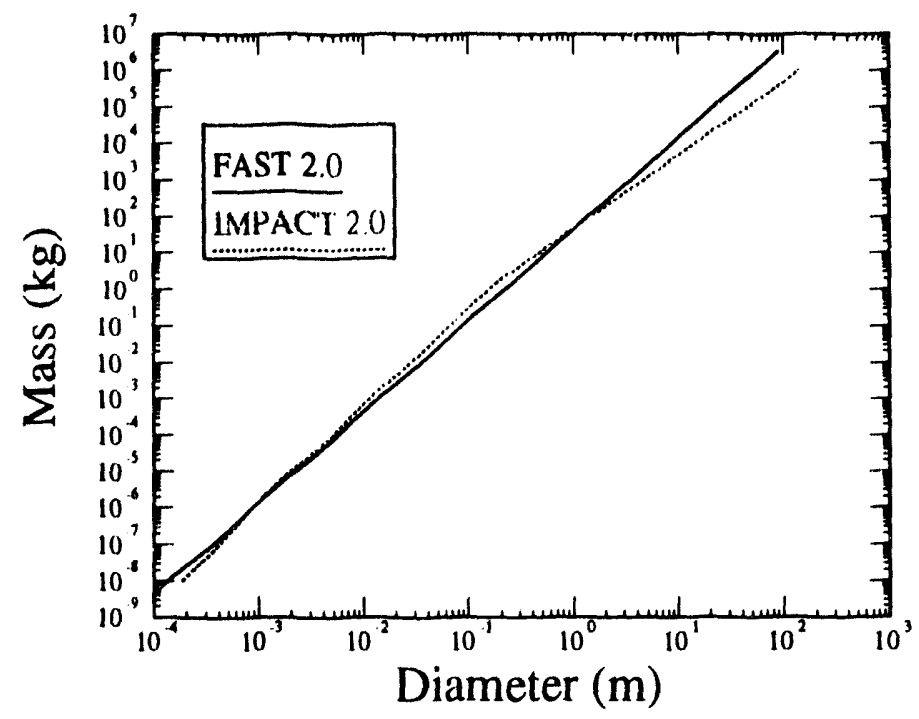

Figure 4.2: Mass/Diameter Relationships for FAST and IMPACT

\section{Fragment Size}

Once the fragment mass is determined, an appropriate fragment size needs to be computed. Both models use a mass to size relationship based somewhat on geometric considerations. IMPACT v2.0 uses a disk, a sphere and an intermediate shape to relate mass $(m)$ and diameter $(d)$ for fragments of density $(\rho)$ and length $(L)$. FAST uses a generic relationship which is calibrated to a sphere for diameters between one and two millimeters. The IMPACT relationships ${ }^{14}$ are given by:

$$
m=\left\{\begin{array}{c}
\frac{\pi \rho L d^{2}}{4} \\
c d^{b} \\
\frac{\pi \rho d^{3}}{6}
\end{array}\right.
$$

where $b$ and $c$ are empirical constants. The mass/size relationship in FAST is given by:

$$
d=(m / f)^{1 / g}
$$


where $f$ and $g$ are empirical constants. Figure 4.2 shows how the mass/size relationships of the two models compare. It represents the most up-to-date comparison. A previous attempt ${ }^{16}$ to compare the two models has an incorrect FAST model and had incorrect values for the IMPACT constants $b$ and $c$. The IMPACT relationships were obtained directly from a recently obtained source code of the breakup model.

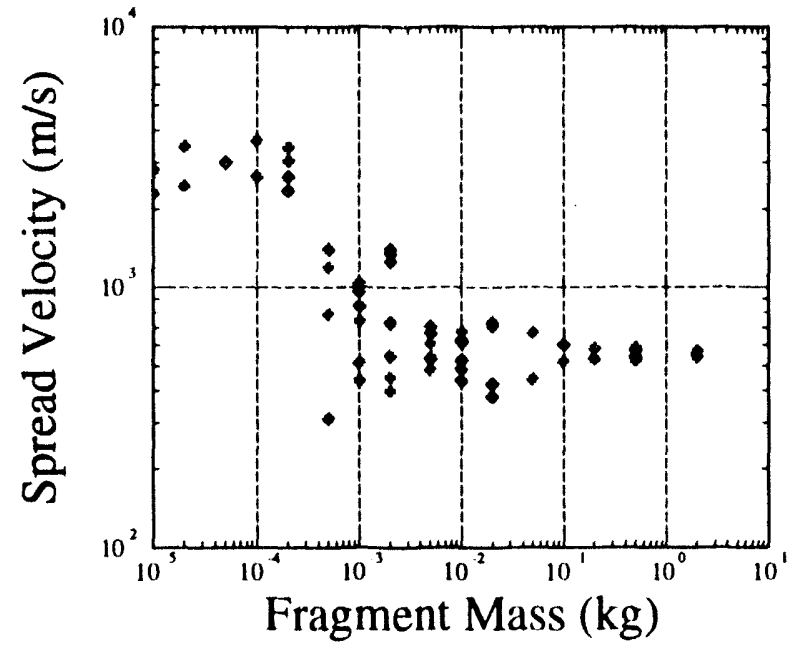

Figure 4.3: IMPACT Spread Velocity Distribution

\section{Eragment Velocity}

Both models compute a fragment "characteristic" velocity that can be thought of as the fragment average incremental velocity. Both models account for a spreading velocity, in which fragments nearly the same size spread from each other. Each model computes the spread velocities in slightly different ways. IMPACT v2.0 uses a beta distribution function to model the spread velocity within each of the mass bins. Mass binning is how IMPACT distributes mass. Each mass bin contains an even number of fragments with an approximately logarithmic range of sizes. Each mass bin has a constant characteristic mass, and the characteristic mass in each bin represents mass that ranges to half way between it and the adjoining (above and below) mass bin's characteristic mass. The effects of mass binning on the mass/ velocity distribution is seen in Figure 4.3. FAST uses a lognormal probability distribution with the characteristic velocity as the means to assign a random spread velocity to each fragment (Figure 4.4). Since mass binning is a means of limiting the number of trajectories computed for the smaller sizes, a lack of mass binning in FAST is not seen as a major problem for a study on collateral damage since the damage is caused by the larger pieces. Both models adjust the mass distribution in order to conserve mass. Both models recommend not being used below a closing velocity of about two to three kilometers per second. 


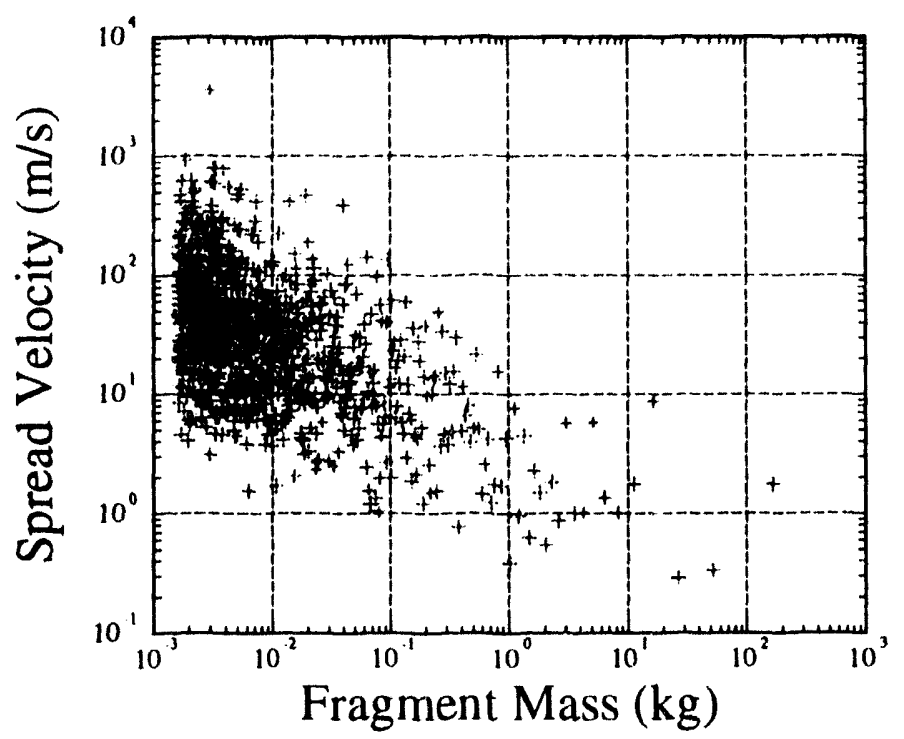

Figure 4.4: FAST Spread Velocity Model

\subsection{FAST Debris Breakup Model}

The FAST empirical debris breakup model is a series of equations developed for the DoD/DNA Orbital Debris Spacecraft Modeling Technology Transfer Program by Dr. Darren McKnight of Kaman Sciences Corporation. FAST is designed to model the breakup characteristics of satellites as they are struck by impacters at hypervelocity speeds. The FAST model is based on mathematical relationships developed over the years by the orbital debris community. Being an empirical model, it is only as good as the test data, which has been hard to come by because of the difficulty in collecting debris and measuring debris velocity. Nonetheless, the orbital debris community feel that FAST is an adequate model because it has been benchmarked against a considerable amount of test data. ${ }^{17}$

Implementing the FAST model requires that three essential relationships be determined: the mass distribution (Equation 4.1), the mass/size distribution (Equation 4.3), and the velocity distribution. The constants $a$ and $b$ in Equation 4.3 are functions of $E M R$, the (collision) energy to mass ratio, and $P$, the collision coupling coefficient. The collision energy, $E$, is calculated with respect to the center of mass of the two vehicles and is given by (in joules):

$$
E=0.5\left\{\frac{M_{p} M_{t}}{M_{p}+M_{t}}\right\} V_{R}^{2}
$$


where $M_{p}$ is the impacter mass $(\mathrm{kg}), M_{t}$ is the target mass $(\mathrm{kg})$, and $V_{R}$ is the relative impact velocity $(\mathrm{m} / \mathrm{s})$. Recent experimental data suggest that target fragmentation is complete when the energy to mass ratio is above a threshold of 35 to 45 joules per gram $(40 \mathrm{~J} / \mathrm{gm}$ nominal $)$.

$$
E M R=\frac{E}{1000 M_{t}}>(35-45 \mathrm{~J} / \mathrm{gm})
$$

If $E M R$ is below the threshold, the fragmentation is considered incomplete, and a different methodology is used.

The variable $P$ is a means for the user to specify the fraction of the collision energy that "couples" into the target. For example, an impact with a liquid filled tank would be given a $P$ value of 1.0 , a full impact with a satellite would have a $P$ value of 0.75 to 1.0 , and a glancing blow with a satellite would have a $P$ value of 0.3 to 0.5 . A smaller value of $P$ has the effect of making a "shallower" mass distribution curve since $P$ is incorporated into the equation for $b$ :

$$
b=0.60+0.15 P\left(\frac{E M R-40}{E M R}\right)
$$

The constant $a$ is found by conserving mass. If the fragmentation process produces $\mathrm{N}$ fragments, then

$$
a=\left(\sum_{n=1}^{N}\left[\frac{1}{n^{1 / b}}\right]\right)^{-b}
$$

Once $a$ and $b$ are determined, the mass $(m)$ of each fragment is computed by solving Equation 4.1 for integer values of $C N$ (as in the HE option in SAFETIE). Equation 4.3 is used to find a characteristic fragment diameter. The fragment's characteristic velocity $\left(V_{C}\right)$ is a function of $d$, the fragment diameter (and thus the mass) and is given by:

$$
V_{C}=V_{R} C_{0}\left(a_{0} /\left(100 d+a_{0}\right)\right)
$$

where $C_{0}$ is an empirical constant, [1.1 - 1.6] with a 1.3 nominal value and

$$
a_{0}=4.8 \times 10^{-4} \frac{M_{p}}{P M_{t}} E^{0.5}
$$

Equation 4.9 is structured so that $a_{0}$ is used to conserve breakup energy. 
Currently, the debris energy is limited to $40 \%$ of the collision energy. The rest of the energy goes into plastic and material fragmentation. The nominal value of 1.3 for the constant $\mathrm{C}_{0}$ reflects the fart that the smaller debris fragments can achieve a velocity greater than the relative impact velocity. A log-normal probabilistic distribution with $V_{C}$ as the mean velocity is used to assign a random spread velocity. Figure 5.4 depicts a typical spread velocity distribution for the LEAP4 flight test conditions with a $P$ value of 0.75 , which represents the recommended value that gives the most velocity spread. The stated uncertainties for the velocity model are $\pm 100 \%$.

If the intercept EMR does not exceed the nominal threshold value of 40 joules/gm, a different methodology is used. The mass is divided into two different distributions: the part that has the power law distribution and is considered ejecta, and a part which has an exponential distribution derived from the Mott fragmentation theory discussed in Chapter 2 and is considered as incomplete fragmentation. The new ejecta mass $\left(M_{e}\right)$ is defined by:

$$
M_{e}=\frac{M_{t}(E M R)}{E M R_{t h}}
$$

where $E M R_{t h}$ is the threshold $E M R$ value (nominally 40 joules/gm).

The ejecta mass distribution is found by substituting $M_{e}$ for $M_{t}$ in the previous power law distribution equations. The incomplete fragmentation mass $\left(M_{b}\right)$ is found by subtracting the ejecta mass from the total mass.

$$
M_{b}=M_{t}-M_{e}
$$

The exponential distribution is similar to Equation 2.1 and has the form:

$$
C N=T M_{b} \mathrm{e}^{-\frac{\sqrt{m_{f}}}{U}}
$$

where, again, $C N$ is the cumulative number, $m_{f}$ is the fragment mass (grams), and $T$ and $U$ are constants with nominal values of $5 \times 10^{-5}$ and 0.04 respectively. The diameter and characteristic velocity of each of these fragments are found using Equations 4.3 and 4.8, respectively. Currently, all FAST constants are set to their nominal values (unless otherwise noted).

As in the other SAFETIE debris generation options, the vehicle's state vector at the event (intercept) time are needed to compute each fragment's velocity. Since the initial utilization of SAFETIE for the LEAP range safety study required that the results of the Monte Carlo analysis on the vehicles' state vectors be obtained from Orbital Science Corporation (OSC), a more "standard" input format for the state 
vectors is assumed. The state vectors are assumed to be in Earth Centered Inertial (ECI) coordinates. The state vectors, consisting of time, three position coordinates, and three velocity coordinates, are in separate, user-defined files for each vehicle. The only other information users have to supply is the mass of each vehicle, the total number of fragments (complete breakup only), and a value for $P$, the energy coupling coefficient. The size of the smallest fragment is determined how many fragments are computed. The two major concerns in the LEAP range safety study for determining minimum fragment size were human injury and damage to nonparticipating commercial aircraft. After a considerable amount of investigation, $\mathrm{Cole}^{5}$ decided that a reasonable threshold impact kinetic energy (KE) was $11 \mathrm{ft}-\mathrm{lbs}$. That is, only fragments impacting with more than $11 \mathrm{ft}$-lbs of $\mathrm{KE}$ were to be considered hazardous to personnel. He also concluded that the threshold diameter for fragments considered hazardous to aircraft was one centimeter. Surprisingly, the latter constraint required a much smaller fragment to be included in the analysis. The footprints for debris fragments generated by SAFETIE from ten typical Monte Carlo LEAP intercepts are shown in Figure 4.5. The complete range safety analysis is in Reference 5.

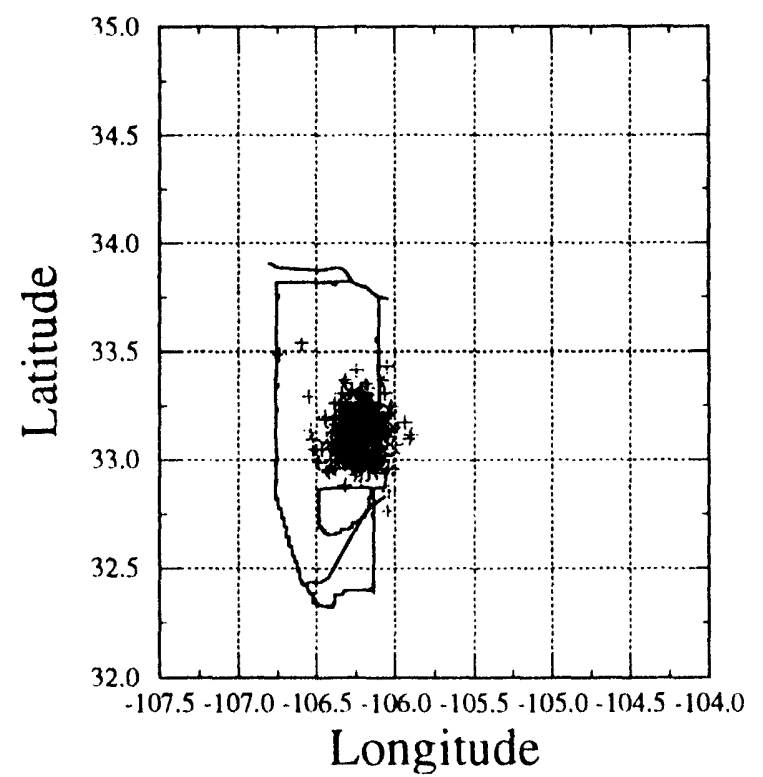

Figure 4.5: LEAP Debris Dispersion for Ten Monte Carlo Intercepts 


\section{Non-Debris SAFETIE Options}

The ability to use SAFETIE to conduct range safety studies for a wide range of problems is extended not only by the various options for generating debris but also by some of the options for handling vehicle state vectors, probabilistic wind and atmosphere models, and by the ability to parallel process trajectories. Users also have the options to use random sampling or a more efficient, stratified sampling technique known as Latin hypercube sampling ${ }^{18,19}$ (LHS) to generate the random variables in SAFETIE. Latin hypercube sampling has been used in the performance of probabilistic risk assessments (PRA) for nuclear power plants. LHS essentially divides the range of each random variable into $n$ non-overlapping intervals, each of which has a value is selected at random (where $n$ is the sample size). Doing so allows LHS to reduce the sample size of the PRA from tens of thousands to the order of 200250 for the same confidence interval. In addition to these options, users also have the ability to override AMEER defaults in SAFETIE. This allows, for example, users to build custom AMEER output files and to chose different atmosphere models within AMEER.

\subsection{Vehicle State Vector Options}

There are three different ways in which the vehicle's state vector(s) are handled in SAFETIE. In all the SAFETIE debris options, the debris fragment's incremental velocity is converted to the geodetic reference frame and added to the vehicle's geodetic velocity as defined by the state vector. The first option assumes that there is just a single state vector and is initiated by setting the trajectory option flag to single. This option would be appropriate for studying the effects of a breakup at a critical location such as the nominal apogee or at a critical time such as the nominal start of a second stage, for example. The state vector for this option consists of (geodetic) altitude, latitude, longitude, total velocity, current horizontal and vertical flight path angles, a reference horizontal flight path angle, and three geodetic-tobody Euler angles. The second option assumes that the time of the event is a uniformly random variable. Accordingly, time has been added to the state vectors, which are assumed to be in a separate, user-specified file. The minimum and maximum values of time are automatically computed in SAFETIE, and the random time value stays strictly between those two values. The trajectory option flag is set to random to initiate this option. This option is useful when a small time step is required to define the trajectory, but the user does not want to generate debris at every time step. The ZEST range safety analysis used this option. The third option reads and uses all the state vectors that are in a user-specified file. The trajectory option flag is set to multi to initiate this option.

The advantage of this third option is that users can include the effects of offnominal trajectories in their range safety analysis, as was done for both the STARS 
and the LEAP range safety analyses. For the STARS analysis, a covariance matrix was used to model the off-nominal position and velocity vectors just as the tumble turn failure mode occurs. This was done in one second increments for between 18 and 38 seconds into the third stage burn (for reasons previously discussed). For a given tumble turn failure mode, 151 trajectories at each second were computed to compute the state vectors for SAFETIE (resulting in 3171 state vectors per tumble turn failure mode). For the LEAP analysis, a Monte Carlo analysis resulted in 200 off-nominal state vectors for both the LEAP and target vehicles.

For the third state vector option, users also have the option of adding the velocity due to the vehicle's angular velocity (i.e., $\vec{\omega} \times \vec{r}$, where $\vec{\omega}$ is the vehicle's angular velocity vector and $\vec{r}$ is the vector between the center of gravity (cg) of the vehicle and the cg of the fragment) to the fragment's total velocity. For a failure mode such as a hard-over nozzle, this velocity could be on the order of $200 \mathrm{ft} / \mathrm{sec}$. This option is mainly responsible for the fragment impacts that are on the edge of the distribution in Figure 3.4.

\subsection{Atmosphere and Winds Options}

Along with various options to generate debris and to handle state vectors, an optional atmosphere model and various optional wind models are available in SAFETIE. The atmosphere model correlates density variations from a nominal value at different altitude levels with each other using a covariance matrix. It is the same model used in Reference 8 . The model also uses normally distributed pressure profile at the highest altitude level to be able to obtain a probabilistic pressure value (pressure and density are all that are required for a user-specified atmosphere model in AMEER). The pressure and density at this altitude level and density at the next lowest are used to integrate pressure to the next lowest level in an iterative scheme. For potential users of this option, a separate computer code that computes the density variations covariance matrix from atmospheric observations is available. Experience has shown, however, that the debris impacts are more wind-driven than density-driven. Consequently, there are three options for describing the probabilistic wind profiles in SAFETIE.

The first option treats the wind observations at each altitude level as independent from each other. All that is required is a mean and a standard deviation of the wind at each altitude level for each wind direction. The second option is based on the Range Reference Atmosphere found in References 20 and 21. The north/south winds and the east/west winds are modeled as being correlated at each altitude level. This options need five parameters at each altitude level: two means, two standard deviations, and a correlation coefficient. Fortunately, these numbers are available for a number of test ranges and for each month of the year. This option was used in the STARS and LEAP analyses. The final option correlates the wind deviations from the nominal value at each altitude level with each other using a covariance matrix, just 
like the atmosphere option. It is the same wind option in Reference 8. Again, a separate computer code that computes the covariance matrix from wind observations is available. All probabilistic atmosphere and winds options are set such that all debris fragments from a given Monte Carlo event experience the same environment. That is, the fragments from Monte Carlo explosion number 3 all experience the same wind profile, but the wind profile for explosion number 4 is different.

\subsection{Other Options}

The ability to compute fragment trajectories in a parallel processing environment is one of the most productive features in SAFETIE. All that is required is an ability to access other workstations/computers. Since all trajectories are independent of each other, the efficiency is $100 \%$. SAFETIE users are allowed to pick: the "base name" of the subdirectories to which the AMEER input file are sent, the "index" of the first subdirectory, the number of events to be put in each subdirectory, and of course, the total number events to be investigated. Users are responsible for creating each subdirectory to which SAFETIE will write. For example, in the ZEST analysis, 1000 explosions were investigated. Since about 35 workstations were available for processing the trajectories, 30 explosions were computed in each subdirectory. The name zest was picked as the "base name" of the subdirectories, and the starting index was 11. SAFETIE required that subdirectories zest 11 through zest 44 have been created prior to execution. Each workstation needed about ten hours to compute all the trajectories in its subdirectory. This meant the analysis $(128,000$ trajectories) could be done overnight without interrupting anyone during normal working hours.

Latin hypercube sampling (LHS) is a technique used by SNL personnel who are performing probabilistic risk assessment (PRA) for nuclear power plants. This assessment can be quite complex, and Monte Carlo techniques have to be quite restrictive in sample size because of the large computational times required for just one sample. LHS is a much more efficient way to conduct a PRA. It divides the range of each variable into $n$ (sample size) non-overlapping interval from which a sample is drawn. Reference 19 shows that a sample size of 200 for a LHS analysis of a power plant, rather than tens of thousands for a Monte Carlo analysis was adequate for repeatability of both uncertainty and sensitivity studies. The approximate sample size for a range safety study using LHS is still under investigation.

It is very probable that users of SAFETIE may wish to investigate certain conditions or variables not foreseen by the author. Consequently, the ability to override AMEER defaults in SAFETIE has been incorporated. The file user table is available as means of overriding any AMEER definition in SAFETIE for such things as changing the default atmosphere (15NANL) or the default output table (AMEER Table 1). Users can also include such things as constant wind profiles in the file. The current staging value (at impact) of 0 feet altitude can also be overridden. 


\section{Conclusions}

SNL has long been involved with flight tests of rocket systems and consequently with verifying their safety. Because of limited computer resources, previous range safety analyses would only investigate a limited number of off-nominal trajectories to qualify the safety of a system. A new computer code, SAFETIE, has been developed that uses Monte Carlo techniques and parallel processing to quantify the safety of rocket flight tests in which debris is generated. The debris model consists of determining a size, shape, mass, and incremental velocity for each debris fragment. SAFETIE essentially generates a series of input files for the AMEER trajectory code. The impact location is used by another code (PDF) to generate probability density contours and casualties expectations for areas of interest. SAFETIE can be used for systems with HE onboard, for systems that are purposely destroyed, or for breakups caused by the impact of two vehicles. The models used to generate debris for each of these types of events have been fully described. The versatility of SAFETIE is further enhanced by options for vehicle state vectors, probabilistic atmosphere and wind models, and the ability to override AMEER defaults in SAFETIE. Examples for each type of debris generating event were given. This methodology has already been accepted by KMR and WSMR. 


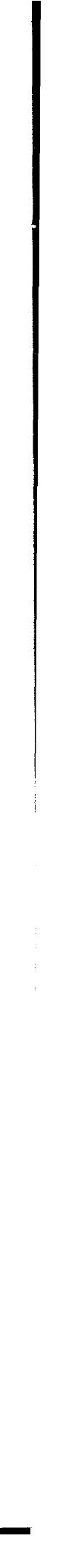




\section{References}

[1] R. A. LaFarge, Using Monte Carlo Techniques and Parallel Processing for Fragmentation Analysis of Explosive Payloads, AIAA -92-0653, 30th Aerospace Sciences Meeting and Exhibit, Reno, Nv, Jan. 6-9,1992.

[2] D. L. Keese, Range Safety Analysis for the ZEST Flight Test Program, May 8, 1991.

[3] D. E. Outka, R. A. LaFarge, Mission Hazard Assessment for STARS Mission 1 (M1) in the Marshall Islands Area, SAND93-0218, Sandia National Laboratories, Albuquerque, New Mexico, July, 1993.

[4] W. A. Millard, D. E. Outka, J. E. White, Trajectory and Flight Safety for the STARS M1 Mission, (Official Use Only), April 26, 1993.

[5] J. K. Cole, R. A. LaFarge, Range Safety Study for LEAP Tests at the White Sands Missile Range, SAND92-2549, Sandia National Laboratories, Albuquerque, New Mexico, March, 1993.

[6] E. J. Meyer, A User's Manual for the AMEER Flight Path-Trajectory Simulation Code, SAND80-2056, Sandia National Laboratories, Albuquerque, New Mexico, October,1981.

[7] R. A. LaFarge, A Description of the Reference Frames and the Coordinate Transformations Used in AMEER, SAND88-0243, Sandia National Laboratories, Albuquerque, New Mexico, March, 1988.

[8] R. A. LaFarge, A Users' Manual for MCPRAM and for the Fuze Options in AMEER, SAND90-0483, May, 1990.

[9] D. E. Randall, Analysis of the Fragmentation Hazard Associated with Explosive Payloads Launched at the Kauai Test Facility, SLA-73-0432, Sandia National Laboratories, Albuquerque, New Mexico, May, 1974.

[10] H. A. Wente, Analysis of the Potential Hazard Associated with the Buaro Experiment, memo, dated May 17,1976.

[11] L. W. Langton, Ed., Textbook of Ballistics and Gunnery: Volume I, Her Majesty's Stationery Office, London, 1987.

[12] D McKnight, Fragmentation Algorithms for Satellite Targets (FAST), Version 1.0, Kaman Sciences Corporation, August 1991.

[13] D. McKnight, R. Maher, and L. Nagl, Fragmentation Algorithms For Satellite Targets (FAST) Empirical Breakup Model, Version 2.0, Kaman Sciences Corporation, September 1992. 
[14] M. E. Sorge, and C. G. Johnson, Space Debris Hazard Software: Program IMPACT Version 2.0 User's Guide, TOR-92(2909), The Aerospace Corporation, November 1991.

[15] M. E. Sorge, Space Debris Hazard Software: Program Impact Version 2.0 Breakup Model, Aerospace Report No. TOR-92(2076)-2, April 1992.

[16] Presented by Orion International Technologies, at the Space Debris Analysis Workstation (DAW) Program Review and Working Meeting, Air Force Phillips Laboratory, June 18, 1992.

[17] Dr. William J. Tedeschi, Report from the KE Debris Uncertainty Delphi Meeting, memo to Dr. David Tilson, July 22, 1992

[18] R. L. Iman and M. J. Shortencarier, A FORTRAN 77 Program and User's Manual for the Generation of Latin Hybercube and Random Samples for Use With Computer Models, SAND83-2365, Sandia National Laboratories, Albuquerque, New Mexico, March, 1984.

[19] R. L. Iman and Jon C. Helton, "The Repeatability of Uncertainty and Sensitivity Analyses for Complex Probabilistic Risk Assessments," Risk Analysis 11, 1991

[20] Meteorological Working Group, White Sands Missile Range Reference Atmosphere 0 - $70 \mathrm{KM}$ Altitude, Range Reference Atmosphere Committee, Document 365-83, August, 1983.

[21] Meteorological Working Group, Barking Sands Range Reference Atmosphere 0 - $70 \mathrm{KM}$ Altitude, Range Reference Atmosphere Committee, Document 370-83, August, 1983. 


\section{Distribution}

$\begin{array}{lll}\text { MS0841 } & 1500 & \text { D. J. McCloskey } \\ \text { MS0836 } & 1501 & \text { C. W. Peterson } \\ \text { MS0827 } & 1502 & \text { P. J. Hommert } \\ \text { MS0827 } & 1511 & \text { J. S. Rottler } \\ \text { MS0834 } & 1512 & \text { A. C. Ratzel } \\ \text { MS0835 } & 1513 & \text { R. D. Skocypec } \\ \text { MS0832 } & 1551 & \text { W. P. Wolfe } \\ \text { MS0832 } & 1551 & \text { T. H. Alsbrooks } \\ \text { MS0832 } & 1551 & \text { K. V. Chavez } \\ \text { MS0832 } & 1551 & \text { J. K. Cole } \\ \text { MS0832 } & 1551 & \text { T. M. Jordan } \\ \text { MS0832 } & 1551 & \text { M. W. Kniskern } \\ \text { MS0832 } & 1551 & \text { R. A. LaFarge (30) } \\ \text { MS0832 } & 1551 & \text { W. A. Millard } \\ \text { MS0832 } & 1551 & \text { D. E. Outka } \\ \text { MS0832 } & 1551 & \text { L. R. Rollstin } \\ \text { MS0832 } & 1551 & \text { H. R. Spahr } \\ \text { MS0832 } & 1551 & \text { L. W. Young } \\ \text { MS0832 } & 1552 & \text { C. E. Hailey } \\ \text { MS0833 } & 1552 & \text { R. S. Baty } \\ \text { MS0826 } & 1553 & \text { W. L. Hermina } \\ \text { MS0826 } & 1553 & \text { D. P. Kelly } \\ \text { MS0825 } & 1554 & \text { W. H. Rutledge } \\ \text { MS0443 } & 1561 & \text { H. S. Morgan } \\ \text { MS0437 } & 1562 & \text { R. K. Thomas } \\ \text { MS1392 } & 2713 & \text { L. W. Lathrop } \\ \text { MS0658 } & 2723 & \text { R. G. Hay } \\ \text { MS0455 } & 4100 & \text { G. R. Otey } \\ \text { MS0423 } & 4114 & \text { J. W. Keizur } \\ \text { MS0314 } 9811 & \text { J. L. McDowell } \\ \text { MS0314 } & 9811 & \text { D. E. Salguero } \\ \text { MS0308 } & 9812 & \text { D. L. Keese } \\ \text { MS0312 } & 9814 & \text { W. E. Williamson } \\ \text { MS0312 } & 9814 & \text { R. W. Greene } \\ \text { MS0310 } & 9816 & \text { R. E. Sheldahl } \\ \text { MS0307 } & 9817 & \text { E. W. Reece } \\ \text { MS0307 } 9817 & \text { R. J. Weir } \\ & & \end{array}$

MS9018 8523-2 Central Technical Files MS0899 7141 Technical Library (6) MS0619 7151 Technical Publications MS1119 7613-2 Document Processing for DOE/OSTI (10)

Mr. Dave Bissell USASDC/CSSD-SL-L Huntsville, AL 35807

Mr. Dave Blazosky NR-AM Bldg 300

White Sands NM 88002

Commander, White Sands Missile Range Flight Safety Office (3)

STEWS-NR-CF

White Sands NM 88002

Attn:

$$
\begin{aligned}
& \text { Mr. Curtis Catanach } \\
& \text { Mr. Dave Donahe } \\
& \text { Ms. Leticia Sanchez }
\end{aligned}
$$

Mr. Russell George

Tybrin Corporation 4900 University Square, Suite 28

Huntsville, AL 35816

Mr. Jerry Johnston

Tybrin Corporation

1283-A North Eglin Parkway

Shalimar, FL 32579

Dr. Julius Lilly

USASDC/CSSD-SL-L

P. O. Box 1500

Huntsville, AL 35807 
Mr. Larry Nagl

Kaman Sciences Corporation

2560 Huntington Ave., Suite 200

Alexandria, VA 22303

Mr. Larry Cunningham

Physical Science Laboratory

NMSU

P. O. Box 30002

Las Cruces, NM 88003

Lt. Col. Steve Theriault

SDIO

Department of Defense

The Pentagon

Washington, D. C., 20301-7100

Capt Al Reinhardt

Phillips Lab / WSS

Kirtland AFB

Albuquerque, NM 87117-6008

Mr. A. F. Huters

AFHMET

6609 Rogers Avenue NE

Albuquerque, NM 87109

Orbital Systems Corporation

3380 South Price Rd

Chandler, AZ 85248

Attn: Mr. Greg McCrea

Mr. Steve Miller

Mr. Rex McWaters

The Aerospace Corporation

P.O. Box 9045

Albuquerque, NM 87119
Mr. Marlon Sorge

The Aerospace Corporation

P.O. BOX 92957

El Segundo, CA 90009-2957

Dr. Firooz Allahdadi

Phillips LAb / WSSD

Kirtland AFB

Albuquerque, NM 87117-6008

John L. Parks

Ground \& Flight Safety Section (824-1)

NASA Wallops Flight Center

Wallops Island, VA 23337

Kwajalein Missile Range

P.O. Box 26

San Francisco, CA 96555

Attn: Bob Valencia

Steve LaPoint

Mr. Thomas Wasmund

Target Vulnerability Branch

Code G13

Naval Surface Warfare Center

Dahlgren Division

Dahlgren, VA 22448

Ms. Donna Egner

WL/FIVS/SURVIAC

Wright Patterson AFB 45433-6553

Ms. Lisa Woods

4141 Colonel Glenn Highway

Suite 131

Dayton, OH 45431 
Mr. Walter Thompson

AMSRL-SL-BA

US Army Research Laboratory

Aberdeen Proving Grounds Site

$+$

APG, MD 21005-5066

Headquarters, DNA

Attention: SPSP

(Dr. R. J. Lawrence)

6801 Telegraph Road

Alexandria, VA 22310 

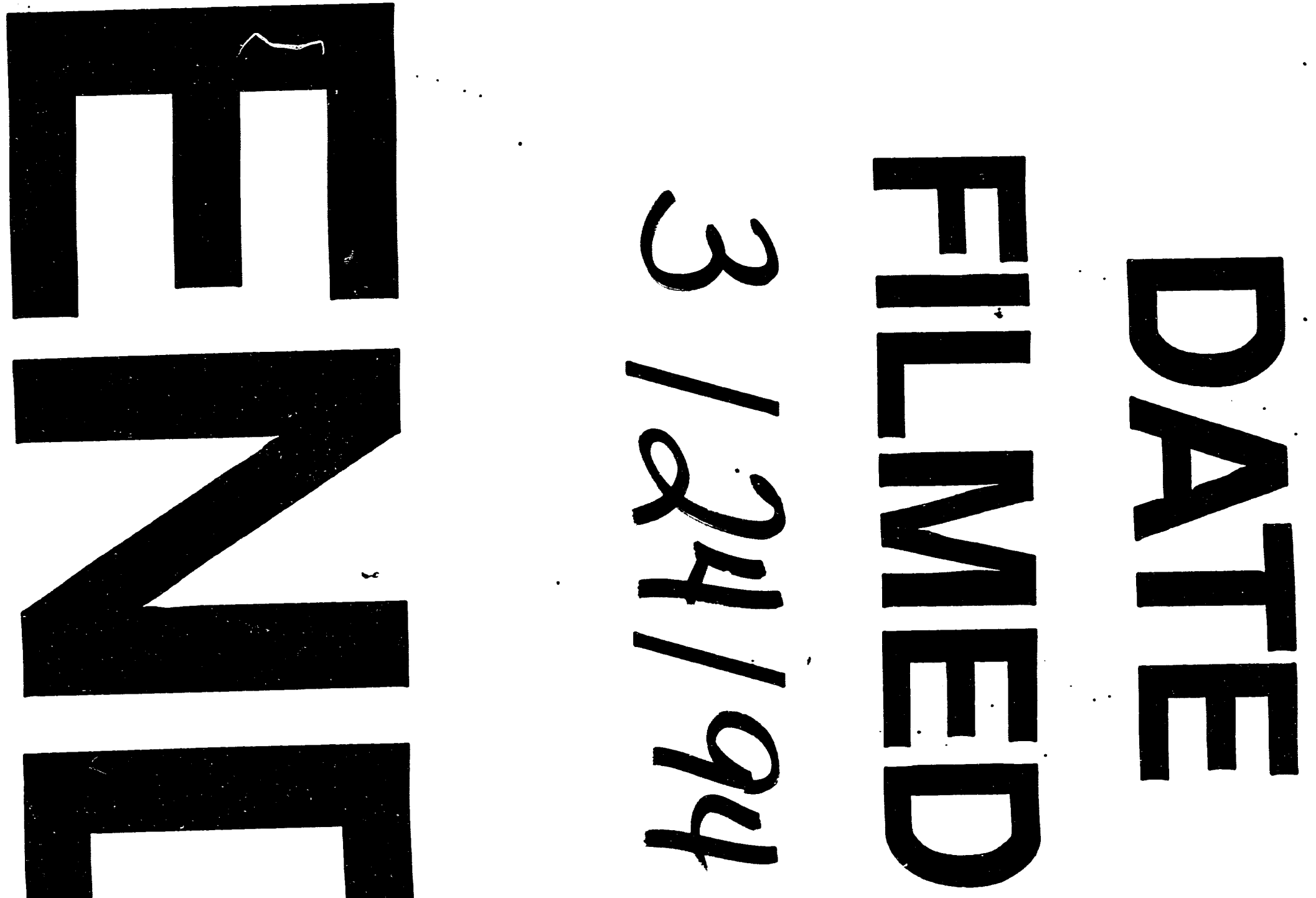
